\title{
ANÁLISE DO PAYBACK DESCONTADO EM SISTEMAS RESIDENCIAIS DE CAPTAÇÃO DE ÁGUA DE CHUVA NO ESTADO DE SANTA CATARINA
}

\section{ANALYSIS OF DISCOUNTED PAYBACK IN RESIDENCIAL RAINWATER COLLECTION SYSTEMS IN THE STATE OF SANTA CATARINA}

\author{
Carlos Eduardo da Silva*E-mail: ceduardosilva@gmail.com \\ Daniel Christian Henrique* E-mail: daniel.henrique@ufsc.br \\ André Toshio Mimura* E-mail: andremimura@gmail.com \\ *Universidade Federal de Santa Catarina (UFSC), Florianópolis, SC, Brasil
}

\begin{abstract}
Resumo: Esse trabalho tem como objetivo central analisar o tempo de recuperação de investimento em sistemas de captação de água de chuva para utilização em residências unifamiliares no estado de Santa Catarina. Como objetivo secundário foi estabelecido a construção de dois softwares de análise em PHP e HTML (SILVA, 2017a, 2017b): (1) Dimensionamento dos Reservatórios de Água de Chuva e (2) Cálculo do Payback Descontado. Foram analisadas residências localizadas em cinco cidades do estado com aplicação de uma análise de sensibilidade para verificar o Payback Descontado com diferentes níveis de pluviosidade, variando o número de habitantes entre três e cinco pessoas, assim como mesclado com vários tamanhos de telhados (com o intuito de averiguar várias configurações residenciais). Constatou-se que é um investimento economicamente viável principalmente para famílias que tenham um grande consumo de água decorrido do seu maior número de residentes e em cidades em que seu custo é elevado. Cidades com um índice pluviométrico maior também são mais favorecidas, pois necessitam uma infraestrutura que exige um investimento inicial menor.
\end{abstract}

Palavras-chave: Água de Chuva. Reaproveitamento de Água. Payback Descontado. Reservatórios de Água. Análise de Investimento.

Abstract: This work aims at the central analysis of the time of recovery of investment in rainwater harvesting systems for use in single family homes in the State of Santa Catarina. As a secondary objective it was installed as a construction of two PHP and HTML analysis softwares (SILVA, 2017a, 2017b): (1) Sizing of Water and Rain Reservoirs and (2) Calculation of Discounted Payback. Residences located in five cities of the State were analyzed with the application of a sensitivity analysis to verify the Discounted Payback with different levels of rainfall, varying the number of inhabitants between three and five people, as mixed with several roof packages (in order to investigate several real estate). It has been found that it is an economically viable investment mainly for families who already have a large water consumption in their largest number of residents and in cities where their cost is high. Cities with a higher rainfall index are also more favored because they require an infrastructure that requires a lower initial investment.

Keywords: Rainwater. Water Reuse. Discounted Payback. Water reservoir. Investment analysis.

\section{INTRODUÇÃO}

A superfície da terra é coberta por $70 \%$ de água. Apesar da sua abundância, apenas 3\% são de composição doce. Desta porcentagem, exatos 1,75\% são de água 
congelada nos polos do globo e o restante compõe água subterrânea, considerada de custo elevado para a sua utilização. Portanto, a parcela que tem um custo mais acessível e facilidade de utilização representa apenas 0,007\% da água existente na terra (CPRM, 2016). Esse é o percentual que pode ser utilizado para os mais diversos fins, desde a irrigação até o consumo in natura pelo ser humano. Consequentemente, vem a ser de grande valia ter-se em mente a importância que isto representa e o cuidado que se faz necessário através da conservação desse bem precioso.

Nesse cenário, a preservação ambiental deveria ser a prioridade, mas ainda não é uma regra. Vide, por exemplo, que a crescente poluição dos mananciais de água faz com que fontes até então julgadas inesgotáveis se tornem cada vez mais escassas. Santa Catarina, que apresenta uma oferta abundante deste recurso natural, ainda não apresenta uma utilização de forma racional. Com precipitações médias anuais variando entre $1.822 \mathrm{~mm}$ a $3.427 \mathrm{~mm}$ conforme a região (INMET, 2017), o estado sofre com outro problema: as enchentes. Este percalço natural é seguido consequentemente por desabrigados e pessoas que podem vir a óbito nas residências em regiões propícias a alagamentos.

Dentro destas tratativas, Khastagir e Jayasuriya (2011) discorrem que as cidades do mundo precisam buscar alternativas para a crescente demanda de água advinda do crescimento econômico e populacional. Para o atingimento deste propósito, é mais que preciso a conscientização também da população no que concerne a preservação e a utilização racional da água, decorrida de sua vital importância para o desenvolvimento humano. Diante dessa necessidade, a adoção de novas tecnologias, como a captação de água de chuva, se mostra como uma das soluções viáveis desse problema, proporcionando à população uma maior oferta de água a um custo atrativo (GHISI; SCHONDERMARK, 2013).

O presente estudo, portanto, visa analisar o tempo de retorno do investimento (payback) da implantação de um sistema de captação de água de chuva em residências unifamiliares com 3, 4 e 5 ocupantes, abordando diferentes áreas de captação de chuva e em diferentes regiões do estado que disponham de um índice pluviométrico variável entre cada uma. Este propósito irá requer, em complemento, o desenvolvimento de dois softwares em PHP e HTML (SILVA, 2017a, 2017b): (1) para análise do dimensionamento dos reservatórios de água de chuva e (2) para o cálculo do Payback Descontado. 


\section{REVISÃO DA LITERATURA}

\subsection{Fluxo de Caixa}

Segundo Padoveze (2005), o fluxo de caixa representa os recursos monetários que entram na empresa em função de recebimentos e saem na forma de pagamentos no percorrer do tempo. Brealey (2002) corrobora a esta assertiva afirmando que além das atividades operacionais no fluxo de caixa, deve-se levar em consideração questões relacionadas aos investimentos e financiamentos da empresa.

Casarotto-Filho e Kopittke (2010) entram na discussão acrescentando que o fluxo de caixa também consiste em mostrar estas entradas e desembolsos de forma gráfica. A simbologia é aplicada sobre setas, apontando para cima nas situações de receitas adquiridas, e para baixo nos momentos de efetivação de gastos (custos e despesas). A linha horizontal representa os períodos de tempo que podem ser semanas, meses, semestres ou anos.

Figura 1 - Fluxo de Caixa

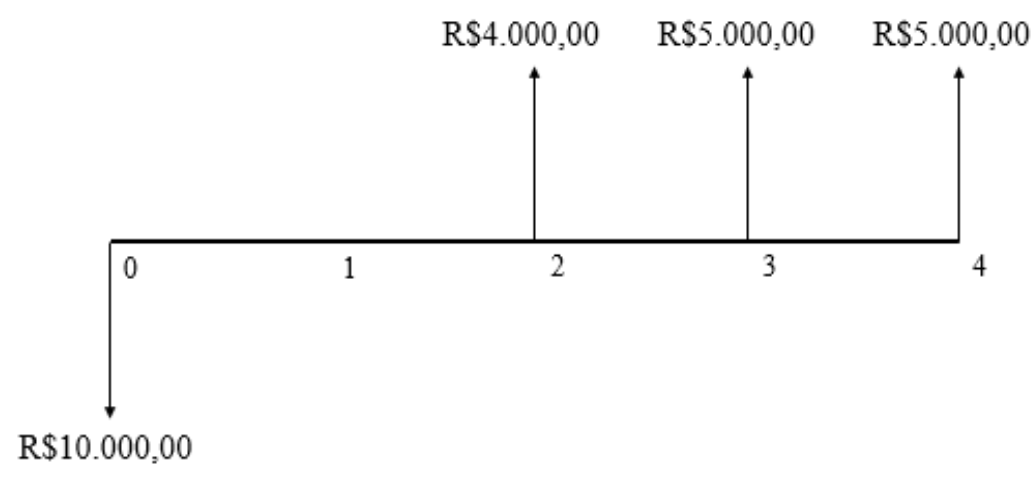

Fonte: Elaborado pelos Autores

Gitman (2010) ainda nomeia essa expressão gráfica como "fluxo de caixa para orçamento de capital", alicerçando seus principais componentes em: investimento inicial, entradas operacionais no caixa e fluxo de caixa terminal. $O$ autor ainda utiliza duas classificações para o fluxo de caixa: convencional e não convencional. A primeira é composta por uma saída no início do período (investimento inicial) e posteriormente apenas uma sequência de entradas, enquanto que a segunda possui uma saída inicial e posteriormente uma continuidade de saídas e entradas. 


\subsection{Taxa Mínima de Atratividade (TMA)}

A TMA representa um percentual que equivale ao valor mínimo para que um projeto consiga incorrer em ganhos. Para uma organização, encontrar o valor dessa taxa de desconto é uma tarefa complicada, devendo levar em consideração questões relacionadas ao prazo e estratégias que a empresa deseja almejar com o projeto em análise (CASAROTTO-FILHO; KOPITTKE, 2010). Por estes motivos existem muitas formas de calculá-la, vindo a ser, aditivamente, um dado comumente utilizado para fins comparativos com a TIR. Uma das formas de estipular o valor deste custo do capital seria tomar como base as taxas de renda fixa (CASAROTTO-FILHO; KOPITTKE, 2010).

Assaf Neto (2012) colabora neste cenário ao informar que a relação entre a projeção do fluxo de caixa operacional e a TMA devem ser condizentes, sendo diretamente decisivo no investimento e no resultado do valor econômico do empreendimento (ou projeto).

\subsection{Indicadores de Viabilidade Financeira}

Para a análise de viabilidade econômica podem ser aplicados diversos indicadores para averiguação de sua pertinência. Todos têm suas fórmulas e resultados oriundos dos dados cooptados no Fluxo de Caixa projetado. Os principais mais abordados são: Payback Simples e Descontado, Valor Presente Líquido (VPL), Taxa Interna de Retorno (TIR) e Valor Uniforme Líquido (VUL). Estes métodos ainda podem vir imersos em análises de cenários e de sensibilidade.

\subsubsection{Payback Simples e Descontado}

De acordo com Gitman (2010), o Payback Simples é um dos métodos mais comuns para analisar investimentos em projetos. A técnica tem como função calcular o período em que a empresa obterá o retorno de seu investimento inicial. Caso esse período de tempo seja menor do que o estipulado pela empresa, tem-se um projeto viável. O autor também comenta que a utilização do método é grande entre pequenos 
empresários por possuir um cálculo trivial, já que não leva em consideração o valor temporal do dinheiro.

Groppelli e Nikbakht (2010) ressaltam que o método não é muito eficiente justamente pela não consideração do valor do dinheiro no tempo, não comportando um bom método para orçamento de capital. Gitman (2010) complementa que se o projeto espera um período mais curto para o retorno de seu investimento, este não terá tantos problemas quanto um que precise de um grande intervalo, já que o tempo é o principal fator de deficiência do método.

A solução é apontada por Souza (2003) ao lembrar que existem outras vertentes mais eficazes dessa técnica. A principal é o Payback Descontado, no qual os fluxos futuros são trazidos a valor presente mediante a aplicação de uma Taxa Mínima de Atratividade. Somente após este passo inicial é possível calcular o tempo de retorno do capital. Uma aplicação simples e exemplificativa é exposta por Camloffski (2014):

Tabela 1 - Fluxo de Caixa de um Projeto (TMA = 10\%)

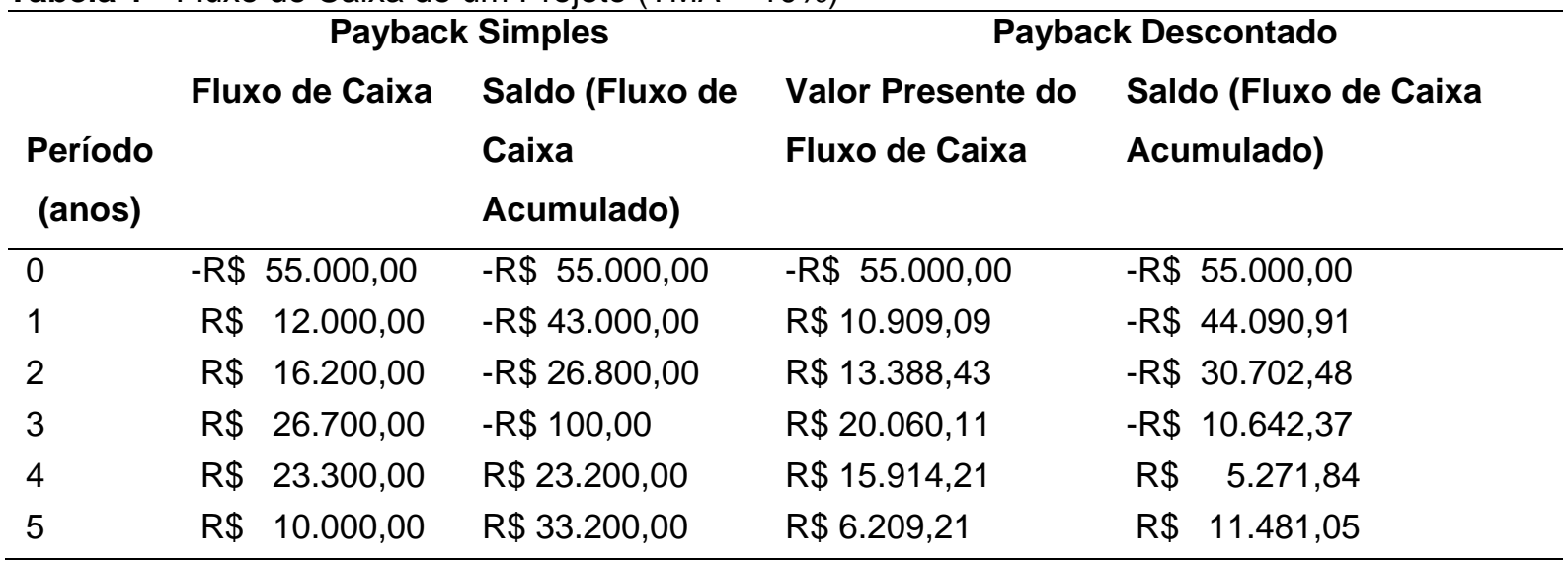

Fonte: Adaptado de Camloffski (2014)

Na composição do seu Payback Simples, basta somar os fluxos de caixa até alcançar o valor investido no momento zero. Desta forma, o investido seria recuperado em três anos mais uma fração do quarto período:

Tabela 2 - Payback Simples de um Projeto

$\begin{array}{ll}\text { Recuperação até o terceiro } & \mathrm{R} \$ 12.000+\mathrm{R} \$ 16.200+\mathrm{R} \$ 26.700 \\ \text { período } & =54.900 \\ \text { Fração do quarto período } & \mathrm{R} \$ 100 / \mathrm{R} \$ 23.300=0,0043 \\ \text { Payback Simples: } & 3,0043 \text { anos }\end{array}$

Fonte: Adaptado de Camloffski (2014) 
Todavia, ao considerar o princípio básico das finanças que institui o valor do dinheiro no tempo, o Payback Descontado passa a ser obtido para o mesmo projeto, agora, somando-se os fluxos de caixa descontados pela TMA (igual a 10\% para o exemplo):

Tabela 3 - Payback Descontado de um Projeto

\begin{tabular}{ll}
\hline Recuperação até o terceiro & $R \$ 10.909,09+R \$ 13.388,43+R \$$ \\
período & $20.060,11=R \$ 44.357,63$ \\
Fração do quarto período & $R \$ 10.642,37 / R \$ 15.914,21=0,67$ \\
Payback Decontado & 3,67 anos
\end{tabular}

Fonte: Adaptado de Camloffski (2014)

Conclui-se que o Payback Descontado necessita de um tempo de recuperação maior em decorrência do desconto do custo do capital. No que concerne ao tempo de recuperação do capital em sistemas de coleta de água de chuva, revisões da literatura aplicadas a variadas cidades do mundo, assim como em outras aplicações da área civil, podem ser lidas em Imteaz et. al (2011), Khastagir e Jayasuriya (2011), Erokuz e Rahman (2010), Guisi e Schondermark (2013) e Villarreal e Dixon (2005).

\subsubsection{Análise de Sensibilidade}

A análise de sensibilidade tem como objetivo modificar as variáveis de entrada que proporcionam alterações nos indicadores financeiros do projeto, podendo influenciar diretamente na lucratividade do empreendimento ou projeto (CASAROTTO-FILHO, KOPITTKE, 2010; ROSS, WESTERFIELD, JAFFE, 2015).

Esta análise tem um importante valor para o setor financeiro, auxiliando-o na previsão dos riscos que o projeto possui e consequentemente na condução das tomadas de decisão. O diagnóstico do risco é realizado a partir dos resultados que o indicador econômico expõe em conformidade às mudanças realizadas nas variáveis do fluxo de caixa (ASSAF NETO, 2012).

\subsection{Dimensionamento dos Reservatórios}

Além do cuidado com a qualidade da água, que deve seguir as tratativas da 
portaria MS2914 do Ministério da Saúde, vem a ser fundamental para uma boa economia de custos na infraestrutura residencial o adequado dimensionamento da capacidade do reservatório no processo de implantação de um sistema de captação de água de chuva em telhados residenciais. Na suposta ocorrência de um sub ou superdimensionamento, o projeto arcará com um grande impacto no tempo de retorno do capital investido.

A Associação Brasileira de Normas Técnicas (ABNT), NBR 15527 de 2007, apresenta vários métodos para o cálculo de reservatórios. Serão aqui delineados apenas o Método Rippl e o Método da Simulação.

\subsubsection{Método de Rippl}

Nesse método é possível utilizar as séries históricas mensais ou diárias de chuva, em conformidade aos procedimentos de cálculos expostos em sequência:

$$
S_{(t)}=D_{(t)}-Q_{(t)}
$$

A ABNT-NBR-15527 (2007, p.6) explica que a equação pode ser entendida da seguinte forma:

\footnotetext{
$Q_{(t)}=C \times$ precipitação da chuva $(\mathrm{t}) \times$ área de captação

$V=\Sigma S_{(t)}$ somente para valores $S_{(t)}>0$

Sendo que: $\Sigma D_{(t)}<\Sigma Q_{(t)}$

Onde:

$\mathrm{S}_{(\mathrm{t})}$ é o volume de água acumulado no reservatório no tempo t;

$Q_{(t)}$ é o volume de chuva aproveitável no tempo t;

$D_{(t)}$ é a demanda ou consumo no tempo t;

$\checkmark$ é o volume de água de chuva acumulado no reservatório;

$C$ é o coeficiente de escoamento superficial.
}

\subsubsection{Método da Simulação}

Este método obedece à seguinte equação:

$$
S_{(t)}=Q_{(t)}+S_{(t-1)}-D_{(t)}
$$


Novamente, a ABNT-NBR-15527 (2007, p.6-7) instaura os seguintes significados para as variáveis acima expostas:

\author{
$Q_{(t)}=C \times$ precipitação da chuva $(t) \times$ área de captação \\ Sendo que: $0 \leq \mathrm{S}_{(\mathrm{t})} \leq \mathrm{V}$ \\ Onde: \\ $S_{(t)}$ é o volume de água no reservatório no tempo $t$; \\ $\mathrm{S}_{(\mathrm{t}-1)}$ é o volume de água no reservatório no tempo $\mathrm{t}-1$; \\ $Q_{(t)}$ é o volume de chuva no tempo $t$; \\ $D_{(t)}$ é o consumo ou demanda no tempo t; \\ $\checkmark$ é o volume do reservatório fixado; \\ $C$ é o coeficiente de escoamento superficial.
}

\title{
3 RESULTADOS
}

\subsection{Instalação do Sistema de Coleta de Água de Chuva.}

Neste primeiro momento é abordada a confecção do sistema de coleta de água de chuva com o intuito de adentrar em todos seus detalhes para uma correta e posterior análise de custos e benefícios econômicos (para cada residência com diferentes números de moradores).

Para se obter uma boa qualidade da água coletada, o sistema deve ser confeccionado seguindo certas regras e sofrer manutenção regular (conforme a ABNT NBR 15527:20071). Segundo Zanela (2015), a água de chuva proveniente de áreas urbanas entra em contato com os poluentes existentes na atmosfera, arrastando-os consigo. Adicionalmente, a água carrega consigo também folhas, galhos de árvores, fezes de pequenos animais ou mesmo animais mortos, existentes nas superfícies dos telhados.

Em atento a estes empecilhos, o sistema de captação de água de chuva proposto procura minimizar os efeitos desses poluentes na água final obtida. Para atender a este propósito são necessários os seguintes componentes para o sistema: área de coleta, calhas, filtro, condutores, dispositivo de descarte de lavagem, cisterna,

\footnotetext{
${ }^{1}$ Os equipamentos não previstos nesta norma devem obedecer sua manutenção conforme especificação do fabricante.
} 
bomba de recalque, filtro de finos e sistema de desinfecção por luz UV. A instalação em uma planta residencial deve obedecer aos padrões abaixo alinhados:

Figura 2 - Esquema da instalação do sistema de coleta de água de chuva

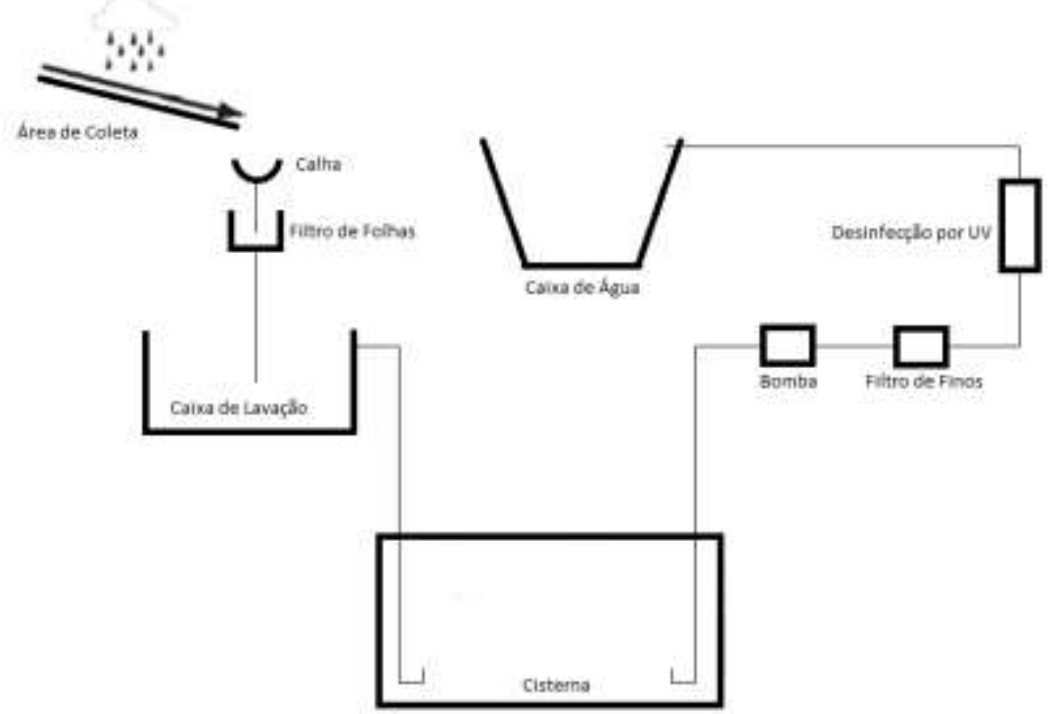

Fonte: Elaborado pelos autores

Para o dimensionamento dos reservatórios acima vistos abordou-se o Método Rippl e o da Simulação, aplicados diretamente no sistema HTML desenvolvido para este propósito. O Método Rippl foi utilizado para calcular o volume inicial do reservatório, que por sua vez veio a ser utilizado no método da Simulação. Este último foi utilizado para o dimensionamento final dos reservatórios

Cabe ressaltar que foi utilizada uma adaptação do Método da Simulação, alterado para considerar a água descartada pelo sistema de lavagem do telhado. A equação (2) passa então a ser escrita como:

$$
S_{(t)}=Q_{(t)}+S_{(t-1)}-D_{(t)}-L_{(t)}
$$

Onde:

$\mathrm{L}_{(\mathrm{t})}$ é o volume de água utilizado para lavação do telhado no tempo t.

\subsection{Resultados dos Cálculos de Payback Descontado}

Para analisar a viabilidade econômica da implantação de um sistema de 
captação de água de chuva em residências unifamiliares foram abordadas diferentes instalações via aplicação da análise de sensibilidade. Para tanto, alterou-se o número de residentes entre 3, 4 ou 5 pessoas, assim como as áreas dos telhados, variando entre $100 \mathrm{~m}^{2}, 150 \mathrm{~m}^{2}, 200 \mathrm{~m}^{2}$ e $300 \mathrm{~m}^{2}$. Tais aplicações foram desenvolvidas em diferentes regiões do estado de Santa Catarina. As cinco cidades contempladas na análise compõem índices pluviométricos distintos e representativos de suas macrorregiões, uma vez que a distribuição das chuvas nesta localidade do país não acontece de forma regular.

Além dessa característica, utilizaram-se municípios que fornecessem um conjunto de dados de chuva tecnicamente em boas condições, isto é, com uma série temporal completa, sem a falta de algum período. As cidades eleitas foram Chapecó, no oeste do estado, Florianópolis, na costa leste, Joinville no norte, Içara no sul e Lages no planalto serrano.

\subsection{1 Índices Pluviométricos}

Os dados referentes à precipitação para Joinville e Içara foram obtidos no site institucional da Agência Nacional de Águas (ANA, 2017), enquanto que para Chapecó, Lages e Florianópolis os dados são oriundos do Instituto Nacional de Meteorologia (INMET, 2017). Para todas as cidades foram considerados como períodos de estudo os dias entre 01/01/2011 e 31/12/2016. Neste intervalo, a precipitação se comportou conforme os dados da Tabela 4 e Figura 2.

Tabela 4 - Precipitação Média Anual

\begin{tabular}{lc}
\hline Cidade & $\begin{array}{c}\text { Precipitação Média Anual } \\
{[\mathrm{mm}]}\end{array}$ \\
\hline Chapecó & 2.231 \\
Florianópolis & 1.841 \\
Joinville & 3.427 \\
Içara & 1.822 \\
Lages & 1.927 \\
\hline Fonte: Adaptado de ANA (2017) e INMET (2017)
\end{tabular}


Figura 2 - Precipitação Média Mensal

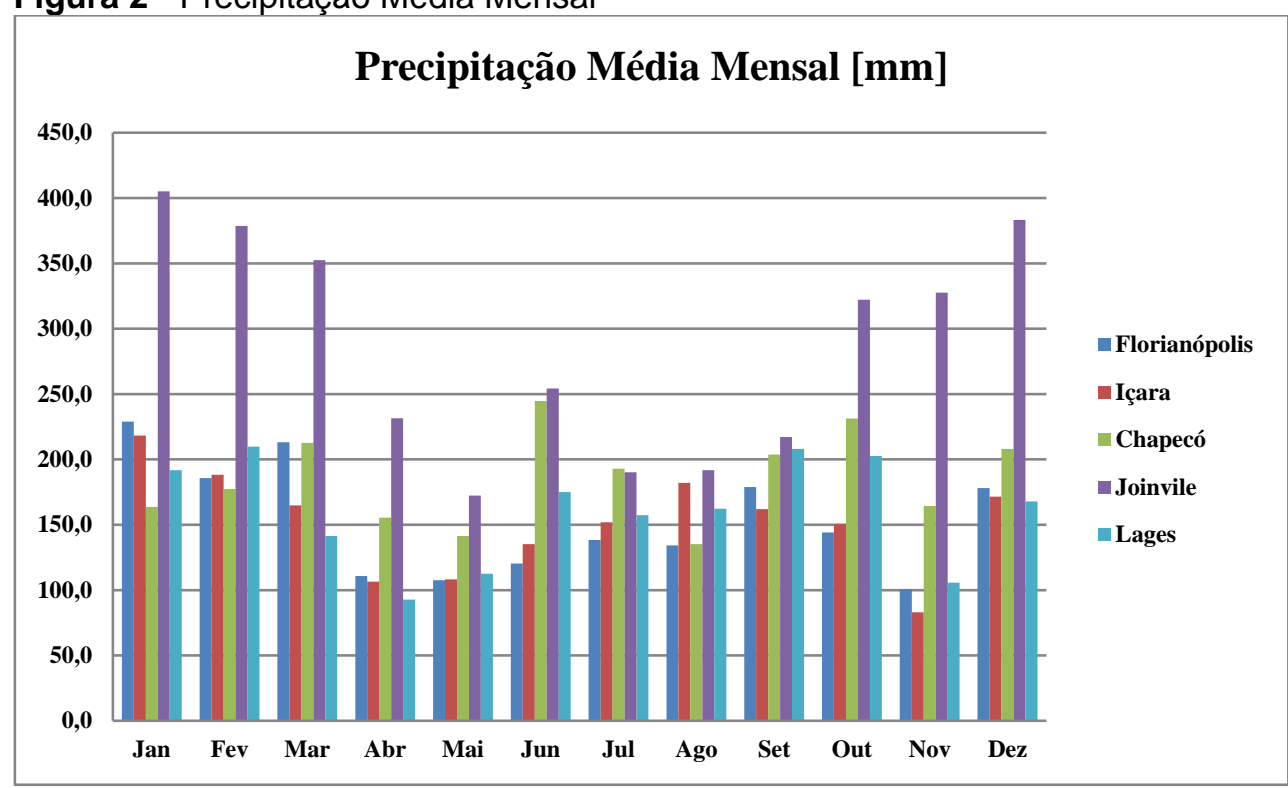

Fonte: Elaborado pelos autores

Uma breve análise dos dados pluviométricos indica que Joinville e Chapecó, detentores dos maiores valores de precipitação média anual, são as localidades que mais podem se beneficiar com o sistema de coleta de água pluvial, uma vez que exigirão menores reservatórios, tornando o custo de infraestrutura mais atraente. Por outro lado, é notório que a estação do inverno é um período com maiores secas, exigindo-se a utilização de reservas de água mais elevadas.

\subsubsection{Demanda de água pluvial}

A demanda de água pluvial será adotada conforme Marinoski (2007), sendo os usos finais de água os adotados para uma família de Classe de Renda 3: consumo de água potável igual a 65,3\%; e, consumo de água não potável equivalente a 34,7\%. Será também considerado o consumo médio de 148,8 litros por dia para Santa Catarina (SNIS, 2017). Na tabela 5 a seguir é apresentado o consumo de água para cada família conforme o número de residentes na qual os litros de água potável são oriundos da substituição pela água de chuva. 
Tabela 5 - Demanda diária de água das famílias

\begin{tabular}{lccc}
\hline & \multicolumn{3}{c}{ Número Pessoas } \\
\cline { 2 - 4 } & $\mathbf{3}$ & $\mathbf{4}$ & $\mathbf{5}$ \\
\hline Consumo Total [L] & 446 & 595 & 744 \\
Consumo água potável [L] & 291 & 388 & 486 \\
Consumo água não potável [L] & 155 & 207 & 259 \\
\hline
\end{tabular}

Fonte: Elaborado pelos autores

\subsubsection{Reservatório Ideal}

O reservatório inferior é a parte mais crítica em todo o sistema de coleta de água da chuva, pois sabidamente é o mais oneroso do processo. O seu correto dimensionamento proporcionará economia tanto na confecção da infraestrutura, uma vez que não será necessário superdimensionar o sistema, como na operação, decorrido da utilização de água da concessionária (visto não haver falta de chuva para suprir as necessidades de consumo).

Para o dimensionamento do reservatório foi desenvolvido o primeiro software aplicado a esta pesquisa com o objetivo fim de auxiliar nesta tarefa (SILVA, 2017a). Existem outros softwares no mercado que executam este cálculo, mas por não se deterem as especificidades em suas funcionalidades designadas a este estudo, optouse por se desenvolver outro.

A figura 3 a seguir mostra a tela onde são informados os dados requisitados $e$ escolha da cidade a ser efetuado o cálculo: consumo diário de água não potável a ser substituída, área do telhado onde será feito a captação da água de chuva, volume da caixa de água de lavagem do telhado. Quanto a este último item, neste estudo será utilizado como parâmetro o equivalente a duas vezes a área do telhado. Finalmente, ainda deverá ser escolhida a localidade a ser estudada para efetuação de uma busca automática no banco de dados do histórico diário de precipitação daquele município: 
Figura 3 - Tela entrada dados do dimensionamento reservatórios

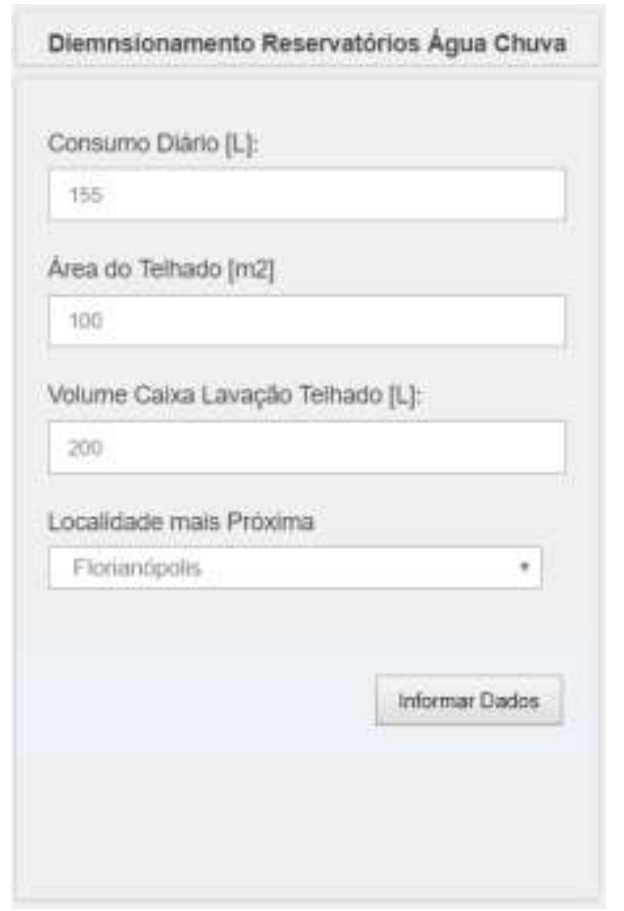

Fonte: SILVA (2017a)

Para utilização do Método da Simulação, adota-se um reservatório com um volume inicial e através do balanço hídrico verifica-se qual a confiança alcançada com o reservatório que está sendo estudado. Como confiança, entende-se a relação entre o número de dias que o reservatório atende a demanda de água sem precisar ser abastecido por uma fonte externa e o período estudado, que neste caso são 6 anos (2.192 dias).

O volume do reservatório a ser adotado como parâmetro inicial para o Método da Simulação é calculado utilizando-se o Método de Rippl. Com base nos dados pluviais, da área do telhado e considerando-se o coeficiente de runoff é calculado o volume de chuva mensal coletado, ou seja, a quantidade de água que abastecerá o reservatório. A diferença entre a demanda necessária e o volume de água de chuva, quando negativa, indica a quantidade máxima de água que poderá ser armazenada naquele mês; e, se positiva, evidencia o quanto será necessário utilizar de água proveniente do reservatório. A soma dos números positivos responde à dúvida sobre qual o tamanho necessário do reservatório para suprir as necessidades daquele ano. Como o estudo abrange uma faixa de seis anos, será determinado um tamanho de reservatório para cada ano, adotando-se o de maior capacidade. 
A tabela 6 mostra os resultados para a cidade de Florianópolis, comportando uma família com três pessoas e área de telhado de $100 \mathrm{~m}^{2}$ no ano 2016. Para esta configuração e ano, o Método de Rippl indica um reservatório com capacidade de 2,1 $\mathrm{m}^{3}$. Efetuam-se os mesmos cálculos para os outros cinco anos, resultando finalmente no volume do reservatório a ser utilizado.

Tabela 6 - Dimensionamento Reservatório utilizando Método de Rippl Local para Florianópolis / ano 2016 / telhado de $100 \mathrm{~m}^{2}$ / 3 habitantes

\begin{tabular}{|c|c|c|c|c|c|}
\hline Mês & $\begin{array}{c}\text { Chuva } \\
\text { Mensal } \\
{[\mathrm{mm}]}\end{array}$ & $\begin{array}{c}\text { Demanda } \\
\text { Mensal } \\
{\left[\mathrm{m}^{3}\right]}\end{array}$ & $\begin{array}{c}\text { Área } \\
\text { Telhado } \\
{\left[\mathrm{m}^{2}\right]}\end{array}$ & $\begin{array}{c}\text { Volume } \\
\text { Chuva } \\
\text { Mensal } \\
{\left[\mathrm{m}^{3}\right]}\end{array}$ & $\begin{array}{c}\text { Diferença } \\
\text { Demanda } \\
\text { e Volume } \\
\text { Chuva } \\
{\left[\mathrm{m}^{3}\right]}\end{array}$ \\
\hline Janeiro & 242,9 & 4,65 & 100 & 19,4 & $-14,8$ \\
\hline Fevereiro & 229,4 & 4,65 & 100 & 18,4 & $-13,7$ \\
\hline Março & 281,3 & 4,65 & 100 & 22,5 & $-17,9$ \\
\hline Abril & 104,9 & 4,65 & 100 & 8,4 & $-3,7$ \\
\hline Maio & 73,5 & 4,65 & 100 & 5,9 & $-1,2$ \\
\hline Junho & 42,9 & 4,65 & 100 & 3,4 & 1,2 \\
\hline Julho & 117,5 & 4,65 & 100 & 9,4 & $-4,8$ \\
\hline Agosto & 77,6 & 4,65 & 100 & 6,2 & $-1,6$ \\
\hline Setembro & 112,9 & 4,65 & 100 & 9,0 & $-4,4$ \\
\hline Outubro & 177,9 & 4,65 & 100 & 14,2 & $-9,6$ \\
\hline Novembro & 47,4 & 4,65 & 100 & 3,8 & 0,9 \\
\hline Dezembro & 252,8 & 4,65 & 100 & 20,2 & $-15,6$ \\
\hline
\end{tabular}

De posse do volume do reservatório obtido por este primeiro método, processase o cálculo pelo Método da Simulação. A partir do reservatório cheio, para cada dia diminui-se o volume de água consumido e soma-se o volume de água coletado. $\mathrm{O}$ volume de água de lavagem do telhado é obtido pelo preenchimento de um reservatório com capacidade, em litros, contabilizado como duas vezes a área em $\mathrm{m}^{2}$ do telhado (no exemplo acima, seria de 200 litros).

O procedimento inicia com o reservatório de lavagem do telhado vazio e o telhado sujo. Após o início das chuvas coleta-se a água suficiente para o preenchimento do reservatório. Somente em um segundo momento desvia-se a água para o reservatório principal, mantendo o reservatório de lavagem cheio. Espera-se dois dias da interrupção das chuvas para esgotar o reservatório (período em que o telhado é considerado limpo) e reiniciar o processo quando começar a chover novamente.

O objetivo, enfim, do Método da Simulação é verificar qual a confiança do sistema para diversos volumes de reservatório, ou seja, contabilizar quantos dias a 
residência é abastecida por água do reservatório, assim como também mensurar os dias que o reservatório ficará desabastecido - neste caso vindo a ser necessário o suprimento de água pela concessionária. Foi considerado como reservatório ideal aquele de menor volume e que proporcionou uma confiança de 100\%.

Os resultados da aplicação no sistema computacional dos dados exemplificativos acima, vistos na figura 3, são apresentados sob a forma de tabelas, expostas a seguir. Inicialmente são apresentados os dados considerados para fazer a simulação, expostos na figura 5:

Figura 5 - Dados Considerados Para a Simulação - Local Florianópolis, Telhado $100 \mathrm{~m}^{2}$, 3 Habitantes

\begin{tabular}{|l|r|}
\hline Consumo Diário [L] & 155 \\
\hline Área do Telhado [M2] & 100,00 \\
\hline Volume Caixa de Lavação [L] & 200 \\
\hline Número Dias Considerados no Estudo & 2192 \\
\hline Total de Chuva no Periodo [mm] & $11.045,20$ \\
\hline Total de Chuva Coletado no Periodo [L] & $\mathbf{8 8 3 . 6 1 6}$ \\
\hline Total Consumido no Periodo [L] & 339.760 \\
\hline Local & Florianopolis \\
\hline Vol. Cisterna Método Rippl & 1000 \\
\hline
\end{tabular}

Fonte: SILVA (2017a).

Na figura 6, em sequência, é apresentado o número de dias que o sistema permanecerá desabastecido para vários volumes de cisterna, a confiança do sistema e os seguintes valores totais: água descartada, água de chuva consumida e água fornecida pela concessionária:

Figura 6 - Análise Para Vários Tamanhos de Cisterna - Local Florianópolis, Telhado $100 \mathrm{~m}^{2}, 3$ Habitantes

\begin{tabular}{|c|c|c|c|c|c|}
\hline Vol Cisterna [L] & Dias Cisterna Vazia & Total Descartado [L] & Total Consumo Chuva [L] & Total Consumo Rede [L] & Confiança $[\%]$ \\
\hline 1.500 & 317 & $\mathbf{5 8 5 , 4 6 6 , 0 0}$ & $290.625,00$ & $49,135,00$ & 85,54 \\
\hline 2.000 & 191 & $567,976,00$ & $310.155,00$ & $29,605,00$ & 91,29 \\
\hline 2.500 & 97 & $\mathbf{5 5 6 . 3 3 9 , 0 0}$ & $324,725,00$ & $15,035,00$ & 95,57 \\
\hline 3.000 & 53 & 550.564 .00 & $331.545,00$ & $8.215,00$ & 97.58 \\
\hline 3.500 & 25 & $546,862,00$ & $335.885,00$ & $3.875,00$ & 98.86 \\
\hline 4.000 & 7 & $544.411,00$ & $338.675,00$ & $1,085,00$ & 99,68 \\
\hline 4.500 & 1 & 543.710 .00 & $339,605,00$ & 155,00 & 99,95 \\
\hline 5.000 & 0 & $5,43,656,00$ & $339.760,00$ & 0,00 & 100,00 \\
\hline
\end{tabular}

Fonte: SILVA (2017a)

A partir do resultado do volume ideal da cisterna, deve-se fazer a análise se realmente vale a pena trabalhar com uma confiança de $100 \%$, pois invariavelmente um pequeno número de dias desabastecido pode resultar em uma cisterna com uma 
diferença grande de volume, proporcionando uma modificação mais significativa de preço.

$\mathrm{Na}$ sequência é apresentado, na figura 7, para o tamanho de cisterna selecionada como ideal (para cada dia considerado no estudo) a data, a precipitação e as quantidades de chuvas: aproveitáveis, utilizadas para a lavagem do telhado, captadas, armazenadas e descartadas na cisterna por overflow e as descartadas na caixa de lavagem. Serão expostos na tabela apenas os primeiros trinta dias desse estudo, com possibilidade de visualização dos resultados completos em SILVA (2017a).

Figura 7 - Balanço Hídrico Para Cisterna 5.000 Litros Local Florianópolis, Telhado 100m², 3 Habitantes

\begin{tabular}{|c|c|c|c|c|c|c|c|}
\hline Data & Precipitaçao [uma & Aproveitável [4] & Armasenado Lavacto [L] C & Captado [L] & Armazenado Cisterna [L] & Descartado Cisterua [L] & Descartado Lavacae [L] \\
\hline $01 \times 01 / 2011$ & 0,00 & 0,00 & 0 & 0,00 & $+845,00$ & 0,00 & $\quad 0.00$ \\
\hline $02 \% 01 / 2011$ & 0,00 & 0,00 & o & 0,00 & $4.690,00$ & 0,00 & 0,00 \\
\hline $03.01 / 2011$ & 6,10 & 455,00 & 200 & 285,00 & $4.823,00$ & 0,00 & 0.00 \\
\hline $04,01 / 2011$ & 0,00 & 0,00 & 200 & 0.00 & $4.668,00$ & 0,00 & 0.00 \\
\hline $05 \times 01 / 2011$ & 0,00 & 0,00 & o & 0,00 & $4.513,00$ & 0,00 & 200,00 \\
\hline $06: 01 / 2011$ & $\$, 00$ & 320,00 & 200 & 120,00 & 4.478 .00 & 0,00 & 0.00 \\
\hline $07 i 01 / 2011$ & 5,60 & 448,00 & 200 & $+48,00$ & $4.771,00$ & 0,00 & 0,00 \\
\hline 08:01/2011 & 0,00 & 0,00 & 200 & 0,00 & $4.616,00$ & 0,00 & 0,00 \\
\hline $09401 / 2011$ & 0,00 & $a, 00$ & 0 & 0.00 & $4,461,00$ & 0,00 & 200,00 \\
\hline 10:01/2011 & 0,00 & 0,00 & a & 0,00 & $4,306,00$ & 0,00 & 0,00 \\
\hline $11 / 01 / 2011$ & 5.20 & 416,00 & 200 & 216,00 & $4.367,00$ & 0,00 & 0,00 \\
\hline $12 / 01 / 2011$ & 3,50 & 250,00 & 200 & 280,00 & $4.492,00$ & 0,00 & 0,00 \\
\hline $1301 / 2011$ & 15,90 & $1.272,00$ & 200 & 1.272 .90 & $5,000,00$ & 609,00 & 0.00 \\
\hline $14: 01 / 2011$ & 9.10 & 728,00 & 200 & 728,00 & $5,000,00$ & 573,00 & 0.00 \\
\hline $15 / 01 / 2011$ & 5,20 & 416,00 & 200 & $\$ 16.00$ & $5,000,00$ & 261,00 & 0,06 \\
\hline $16: 01 / 2011$ & 34.80 & $2.784,00$ & 200 & $2.784,00$ & $5,000,00$ & 2.629 .00 & 0.00 \\
\hline $17,01 / 2011$ & 0,50 & 40,00 & 200 & 40,00 & $4.885,00$ & 0,00 & 0,00 \\
\hline $18.01 / 2011$ & 0,00 & 0,00 & 200 & 0.00 & $4.730,00$ & 0,00 & 0.00 \\
\hline $19.01 / 2011$ & 48.20 & $3,856,00$ & 200 & $3.856,00$ & $5,000,00$ & $3,431,00$ & 0,00 \\
\hline $20001 / 2011$ & 0.40 & 32,00 & 200 & 32.00 & $4.877,00$ & 0,00 & 0.00 \\
\hline $21.01 / 2011$ & 1.60 & 128,00 & 200 & 128,00 & $4.859,00$ & 0,00 & 0,00 \\
\hline $2201 / 2011$ & 144,40 & 11.552 .00 & 200 & $11.552,00$ & $5.000,00$ & $11.247,00$ & 0,00 \\
\hline $2301 / 2011$ & 4.20 & 336,00 & 200 & 336,00 & $5,000,00$ & 181,00 & 0.00 \\
\hline $24,01 / 2011$ & 4,30 & 344,00 & 200 & 34,00 & $5.000,00$ & 189,00 & 0,00 \\
\hline $25001 / 2011$ & 0.00 & 0,00 & 200 & 0.00 & $4.845,00$ & 0,00 & 0.00 \\
\hline $26.01 / 2011$ & 1.80 & 14,00 & 200 & 144,00 & $+.834,00$ & 0,00 & 0.00 \\
\hline $27 / 01 / 2011$ & 0,00 & 0,00 & 200 & 0,00 & $+.679,00$ & 0,00 & 0,00 \\
\hline $2801 / 2011$ & 0.30 & 24,00 & 200 & 24,00 & $4,548,00$ & 0,00 & 0.00 \\
\hline $29: 01 / 2011$ & 0,00 & 0,00 & 200 & 0,00 & $4.395,00$ & 0,00 & 0,00 \\
\hline $30.01 / 2011$ & 1.30 & 104,00 & 200 & 104,00 & $4.342,00$ & 0,00 & 0.00 \\
\hline $31 / 01 / 2011$ & 0.00 & 0,00 & 200 & 0.00 & $4.187,00$ & 0,00 & 0,00 \\
\hline
\end{tabular}

Fonte: SILVA (2017a)

\subsubsection{Custos e benefícios financeiros envolvidos no processo}

Entre os custos que fizeram parte do processo, o principal foi o de infraestrutura visto que contabilizou parte do investimento inicial, incluindo a aquisição dos reservatórios, tubulação de água, calhas e condutores, filtros, bomba, sistema de desinfecção ultravioleta e a mão de obra para instalação desses equipamentos. Esses gastos sofreram variação conforme modificações das variáveis na análise de 
sensibilidade, ou seja, modificando o tamanho do telhado e o número de pessoas residentes no local que farão utilização dessa água.

Além desse desembolso inicial, mensalmente há um custo relativo ao fornecimento de energia elétrica para o bombeamento de água e para a lâmpada de desinfecção ultravioleta. Em contrapartida, existe um benefício financeiro com a economia de água que o sistema proporciona, vindo a ser o valor equivalente a duas vezes a economia desta água. Essa aritmética advém do fato da concessionária cobrar pela utilização do esgoto o igual ao custo da água.

\subsubsection{Custos de implantação do sistema}

Foi levantado um custo para implantação e manutenção do sistema de aproveitamento de água pluvial para cada instalação. Ofertou-se preferência na aquisição dos materiais padronizados que pudessem ser adquiridos através de ecommerce. Essa escolha foi a mais pertinente decorrida da não variação dos custos conforme a cidade onde os materiais serão utilizados, possibilitado pelo custo de transporte ser igual para todo o estado. Os custos a serem considerados para a implantação do sistema são os seguintes:

Reservatórios inferior, superior e dispositivo de descarte de água e lavagem do telhado: foram utilizadas caixas de água de polietileno que podem variar de 150 a 15.000 litros. Os custos dos reservatórios, levantados no mês de setembro de 2017 , foram os constantes na tabela 7 .

Tabela 7 - Custos de Reservatórios

\begin{tabular}{cr}
\hline Volume [L] & Custo [R\$] \\
\hline 15.000 & $4.807,70$ \\
10.000 & $3.141,86$ \\
6.000 & $2.930,90$ \\
5.000 & $1.778,25$ \\
1.000 & 285,49 \\
500 & 139,90 \\
300 & 121,99 \\
150 & 107,90 \\
\hline Fonte: Elaborado pelos autores
\end{tabular}


Conjunto motor bomba centrífuga: foi utilizada uma motobomba de superfície com potência de $0,25 \mathrm{~kW}$ e rendimento variando na faixa de 0,3 a 0,4 conforme a faixa de vazão que a mesma venha a trabalhar e segundo as curvas características da bomba (SCHNEIDER, 2017). O conjunto motor bomba escolhido foi o mesmo para todas as instalações, variando apenas o tempo que o mesmo permanecerá ligado para fornecer a quantidade de água necessária, visto que o menor conjunto atende a todas as instalações. O custo levantado em setembro de 2017 é de $R \$ 317,90$.

Calhas, condutores e acessórios de PVC: variaram a quantidade conforme o tamanho da residência. $O$ custo para cada residência é o apresentado na tabela 8, já computado a mão de obra para instalação do sistema.

\begin{tabular}{cc}
\multicolumn{3}{c}{ Tabela 8 - Custo de Calhas e Condutores } \\
\hline Área Telhado $\left[\mathrm{m}^{2}\right]$ & Custo $[\mathrm{R} \$]$ \\
\hline 100 & $2.475,81$ \\
150 & $2.751,69$ \\
200 & $3.024,57$ \\
300 & $3.472,77$ \\
\hline
\end{tabular}

Fonte: Elaborado pelos autores

Filtro de finos: foi escolhido um filtro que permite a retrolavagem (por facilidade de operação e custo de manutenção) a ser utilizado em todas as residências visto ser o de menor capacidade e atender a todos os requisitos de vazão. O custo do filtro levantado em setembro de 2017 foi de $\mathrm{R} \$ 139,99$.

\subsubsection{Custos de operação do sistema}

Para manter o sistema em funcionamento é necessário o acionamento da bomba e da luz ultravioleta por energia elétrica fornecida pela concessionária, com seus cálculos delineados em sequência:

Consumo de energia elétrica para bombeamento de água: é calculado pela equação 4.

$$
\mathrm{C}_{\text {Energia }}=\mathrm{E} . \mathrm{P}
$$


Onde :

$E=$ Custo unitário da energia elétrica em $R \$ / k W h$

$\mathrm{P}=$ Potência consumida pela bomba em $\mathrm{kWh}$

A potência de bombeamento, por sua vez, é calculada pela equação (5)

$$
P=\frac{\text { w.h.d }}{1000}
$$

Onde:

$\mathrm{w}=$ Potência do equipamento em $\mathrm{W}$

$\mathrm{h}=$ Número de horas de utilização por dia

$\mathrm{d}=$ Número de dias utilizado no mês

Consumo de energia elétrica para sistema de desinfecção por UV: da mesma forma que para a bomba centrífuga, o consumo de energia elétrica do sistema de desinfecção será orientado pelas equações (4) e (5), onde w, agora, será a potência gasta pela lâmpada UV.

O custo unitário de energia elétrica é calculado conforme tabela da concessionária, mostrado na tabela 9, para a classe na qual a residência se enquadra: Tarifa Convencional, Grupo B, sub grupo B1, Residencial Normal.

Tabela 9 - Tarifa Energia Elétrica

\begin{tabular}{ccc}
\hline $\begin{array}{c}\text { Sub } \\
\text { Grupo }\end{array}$ & Classificação & $\begin{array}{c}\text { Energia } \\
\text { R\$/kWh }\end{array}$ \\
\hline B1 & Residência Normal & 0,43142 \\
\hline Fonte: Adaptado de CELESC $(2017)$
\end{tabular}

Ao valor da energia elétrica é acrescido o valor do tributo de ICMS, conforme a tabela 10.

Tabela 10 - Tributo de ICMS Energia Elétrica

\begin{tabular}{cc}
\hline Classe & ICMS \\
\hline Classe Residencial: Primeiros 150 \\
kWh & $12 \%$ \\
\hline Fonte: Adaptado de CELESC (2017)
\end{tabular}


Finalmente, o consumo e o custo da energia elétrica demandada pela bomba e pela lâmpada do sistema de desinfecção estão mostrados na Tabela 11, em função do consumo de água não potável que deverá ser bombeada e desinfectada, para cada caso.

Tabela 11 - Custo e Consumo de Energia Elétrica

\begin{tabular}{lccc}
\hline & \multicolumn{3}{c}{ Número Pessoas } \\
\cline { 2 - 4 } & 3 & 4 & 5 \\
\hline Demanda água não potável [L/Dia] & 155 & 207 & 259 \\
Tempo uso bomba e desinfecção & & & \\
[Horas/mês] & 1,1 & 1,5 & 1,9 \\
Consumo Bomba [kWh/mês] & 0,28 & 0,37 & 0,46 \\
Custo Bomba [R $\$ / \mathrm{mês}]$ & 0,13 & 0,18 & 0,22 \\
Consumo lâmpada desinfecção [w/mês] & 10,21 & 13,63 & 17,06 \\
Custo lâmpada desinfecção [R $\$ / \mathrm{mês}]$ & 0,00 & 0,01 & 0,01 \\
Custo Total Energia Elétrica [R $\$ / \mathrm{mês}]$ & 0,14 & 0,19 & 0,23 \\
\hline
\end{tabular}

Fonte: Elaborado pelos autores

\subsubsection{Benefício Econômico}

O benefício econômico considerado foi igual ao dobro do valor da água substituída, pois o mesmo valor que a concessionária cobra pelo consumo de água, também cobra de taxa de esgoto. Exceção é feita à cidade de Joinville, onde o valor do esgoto é $80 \%$ do valor cobrado pela água. A Tabela 12 contém as tarifas consideradas para cada cidade analisada:

Tabela 12 - Tarifa Água Concessionária

\begin{tabular}{|c|c|c|c|c|c|c|}
\hline Faixa & Consumo & Florianópolis & Içara & $\begin{array}{l}\text { Chapecó } \\
\mathrm{R} \$ / \mathrm{m}^{3}\end{array}$ & Joinville & Lages \\
\hline 1 & $\begin{array}{c}\text { Mensal } \\
\text { Até } 10 \mathrm{~m}^{3}\end{array}$ & 42,19 & 42,19 & 42,19 & 32,91 & 28,27 \\
\hline $\begin{array}{l}2 \\
3\end{array}$ & $\begin{array}{l}11 \text { a } 25 \\
26 \text { a } 50\end{array}$ & $\begin{array}{l}7,7314 \\
10,847\end{array}$ & $\begin{array}{l}7,7314 \\
10,847\end{array}$ & $\begin{array}{l}7,7314 \\
10,847\end{array}$ & $\begin{array}{l}5,81 \\
7,97\end{array}$ & $\begin{array}{l}4,81 \\
6.55\end{array}$ \\
\hline 4 & Maior 50 & 12,9982 & 12,998 & 12,9982 & 7,97 & 6,55 \\
\hline
\end{tabular}

As tarifas para as cidades de Lages e Joinville são menores em comparação àquelas cobradas nas cidades de Florianópolis, Içara e Chapecó, indicando que para as duas primeiras o período de recuperação de capital deva ser maior que as demais.

Os valores das demandas totais de água, água potável e água não potável (a qual será substituída pela água da chuva), assim como seus custos correspondentes, encontram-se nas tabelas 13, 14 e 15. 
Tabela 13 - Custo e Consumo de Água

Cidades de Florianópolis, Içara e Chapecó

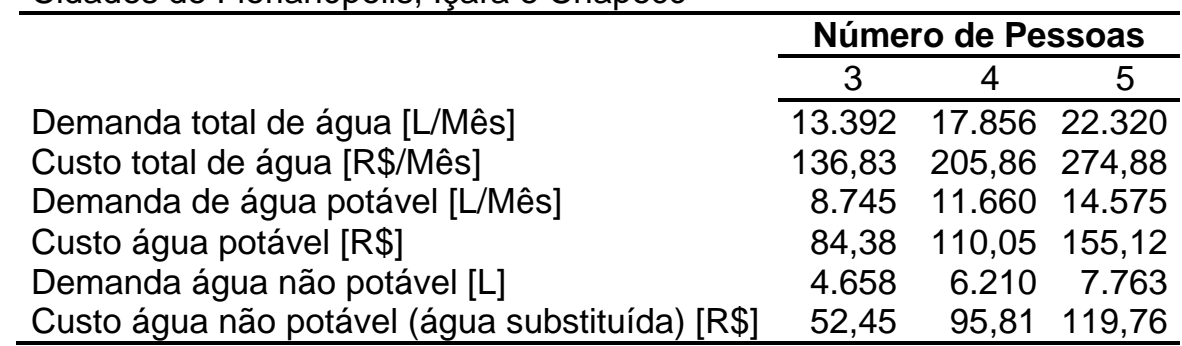

Fonte: Elaborado pelos autores

Tabela 14 - Custo e Consumo e Água

Cidade de Joinville

\begin{tabular}{lrrr}
\hline & \multicolumn{3}{c}{ Número de Pessoas } \\
\cline { 2 - 4 } & \multicolumn{1}{c}{3} & \multicolumn{1}{c}{4} & \multicolumn{1}{c}{5} \\
\cline { 2 - 4 } Demanda total de água [L/Mês] & 13.392 & 17.856 & 22.320 \\
Custo total de água [R\$/Mês] & 94,71 & 141,40 & 188,08 \\
Demanda de água potável [L/Mês] & 8.745 & 11.660 & 14.575 \\
Custo água potável [R $\$$ ] & 59,24 & 76,60 & 107,08 \\
Demanda água não potável [L] & 4.658 & 6.210 & 7.763 \\
Custo água não potável [R\$] (água substituída) & 35,47 & 64,80 & 81,00 \\
\hline
\end{tabular}

Fonte: Elaborado pelos autores

Tabela 15 - Custo e Consumo de Água

Cidade de Lages

\begin{tabular}{|c|c|c|c|}
\hline & \multicolumn{3}{|c|}{ Número de Pessoas } \\
\hline & 3 & 4 & 5 \\
\hline Demanda total de água [L/Mês] & 13.392 & 17.856 & 22.320 \\
\hline Custo total de água [R $\$$ /Mês] & 89,17 & 132,11 & 175,06 \\
\hline Demanda de água potável [L/Mês] & 8.745 & 11.660 & 14.575 \\
\hline Custo água potável $[R \$]$ & 56,54 & 72,51 & 100,55 \\
\hline Demanda água não potável [L] & 4.658 & 6.210 & 7.763 \\
\hline Custo água não potável [R\$] (água substituída) & 32,63 & 59,61 & 74,51 \\
\hline
\end{tabular}

Fonte: Elaborado pelos autores

\subsubsection{Período de recuperação do capital}

O método de tempo de recuperação de investimento, o Payback Descontado, foi o selecionado por tratar-se de um sistema utilizado para geração de economia financeira nas contas de uma família que tenderá a se manter por toda uma vida na residência. Assim, há uma maior preocupação delas em saber sobre quanto tempo esse projeto residencial se pagará do que efetivamente quanto obterá de lucro (ou seja, VPL) na forma de economia até o fim de suas vidas. De posse do investimento inicial e do benefício econômico obtido com o sistema de recuperação de água de chuva é possível, então, saber quantos meses demorará para recuperar o capital. 
O investimento terá sido recuperado no período em que o Fluxo de Caixa passa a ser positivo, ou seja, quando o somatório dos benefícios econômicos descontados os custos, trazidos a valor presente mediante desconto da TMA, for maior que o investimento feito inicialmente.

Para executar os cálculos foi implementado o segundo sistema em PHP e HTML que informa para cada período o Fluxo de Caixa e o Valor Presente de cada parcela mensal (SILVA, 2017b), a partir do abastecimento dos dados do investimento inicial, dos benefícios econômicos, das despesas mensais de manutenção e da TMA. A taxa de desconto adotada neste trabalho é de 0,655 \% ao mês, equivalente a 97\% do CDI de $8,14 \%$ ao ano. Este percentual era o disponível na data de efetivação da pesquisa. Os campos para estas informações de entrada no software podem ser vistos na figura abaixo:

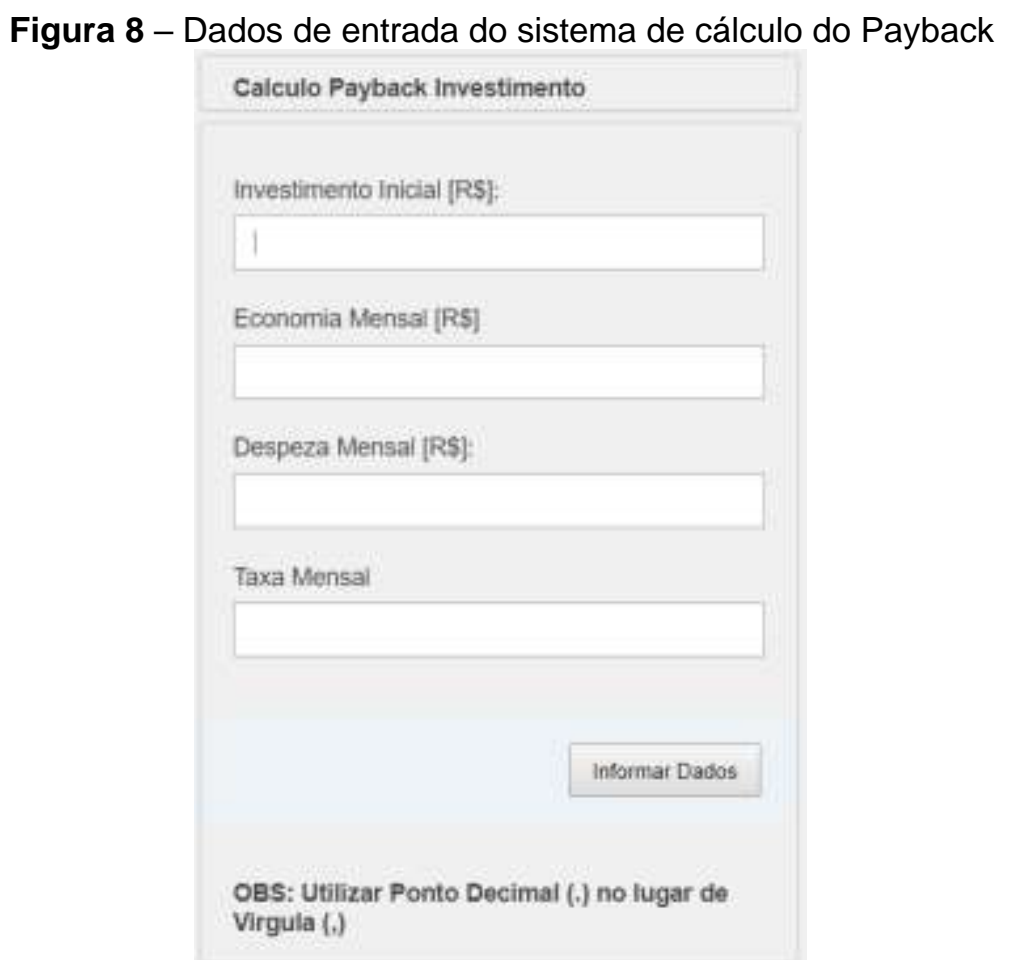

Fonte: SILVA (2017b)

As tabelas de cálculos dos Paybacks Descontados são extensas e demandariam amplo espaço. Portanto, será destacado apenas um exemplo ilustrativo (os demais serão apenas encalçados nos quadros de resumos): residência com $300 \mathrm{~m}^{2}$ de telhado, 5 habitantes e localizada em Florianópolis, mostrada na tabela 16. 
Tabela 16 - Período de Recuperação de Capital

Fluxo de

Caixa

Período Acumulado Beneficio Presente

\begin{tabular}{cccc}
\hline 0 & $-7.762,82$ & 0 & 0 \\
1 & $-7.644,07$ & 119,53 & 118,75 \\
2 & $-7.526,09$ & 119,53 & 117,98 \\
3 & $-7.408,88$ & 119,53 & 117,21 \\
4 & $-7.292,43$ & 119,53 & 116,45 \\
5 & $-7.176,74$ & 119,53 & 115,69 \\
6 & $-7.061,80$ & 119,53 & 114,94 \\
7 & $-6.947,61$ & 119,53 & 114,19 \\
8 & $-6.834,16$ & 119,53 & 113,45 \\
9 & $-6.721,45$ & 119,53 & 112,71 \\
10 & $-6.609,48$ & 119,53 & 111,98 \\
11 & $-6.498,23$ & 119,53 & 111,25 \\
12 & $-6.387,71$ & 119,53 & 110,52 \\
13 & $-6.277,90$ & 119,53 & 109,8 \\
14 & $-6.168,81$ & 119,53 & 109,09 \\
15 & $-6.060,43$ & 119,53 & 108,38 \\
16 & $-5.952,76$ & 119,53 & 107,67 \\
17 & $-5.845,79$ & 119,53 & 106,97 \\
18 & $-5.739,51$ & 119,53 & 106,28 \\
19 & $-5.633,92$ & 119,53 & 105,59 \\
20 & $-5.529,02$ & 119,53 & 104,9 \\
21 & $-5.424,81$ & 119,53 & 104,22 \\
22 & $-5.321,27$ & 119,53 & 103,54 \\
23 & $-5.218,41$ & 119,53 & 102,86 \\
24 & $-5.116,21$ & 119,53 & 102,19 \\
25 & $-5.014,68$ & 119,53 & 101,53 \\
26 & $-4.913,81$ & 119,53 & 100,87 \\
27 & $-4.813,60$ & 119,53 & 100,21 \\
28 & $-4.714,04$ & 119,53 & 99,56 \\
29 & $-4.615,13$ & 119,53 & 98,91 \\
30 & $-4.516,86$ & 119,53 & 98,27 \\
31 & $-4.419,23$ & 119,53 & 97,63 \\
32 & $-4.322,23$ & 119,53 & 96,99 \\
33 & $-4.225,87$ & 119,53 & 96,36 \\
34 & $-4.130,14$ & 119,53 & 95,74 \\
35 & $-4.035,02$ & 119,53 & 95,11 \\
36 & $-3.940,53$ & 119,53 & 94,49 \\
37 & $-3.846,65$ & 119,53 & 93,88 \\
38 & $-3.753,38$ & 119,53 & 93,27 \\
39 & $-3.660,72$ & 119,53 & 92,66 \\
40 & $-3.568,66$ & 119,53 & 92,06 \\
41 & $-3.477,20$ & 119,53 & 91,46 \\
42 & $-3.386,34$ & 119,53 & 90,86 \\
\hline
\end{tabular}

Fonte: SILVA (2017b)

\begin{tabular}{cccc}
\multicolumn{5}{c}{$\begin{array}{c}\text { Fluxo de } \\
\text { Caixa }\end{array}$} & & Valor \\
Período & Acumulado & Beneficio & Presente \\
\hline 43 & $-3.296,07$ & 119,53 & 90,27 \\
44 & $-3.206,38$ & 119,53 & 89,69 \\
45 & $-3.117,28$ & 119,53 & 89,1 \\
46 & $-3.028,76$ & 119,53 & 88,52 \\
47 & $-2.940,81$ & 119,53 & 87,95 \\
48 & $-2.853,44$ & 119,53 & 87,37 \\
49 & $-2.766,63$ & 119,53 & 86,8 \\
50 & $-2.680,39$ & 119,53 & 86,24 \\
51 & $-2.594,71$ & 119,53 & 85,68 \\
52 & $-2.509,59$ & 119,53 & 85,12 \\
53 & $-2.425,03$ & 119,53 & 84,57 \\
54 & $-2.341,01$ & 119,53 & 84,02 \\
55 & $-2.257,54$ & 119,53 & 83,47 \\
56 & $-2.174,61$ & 119,53 & 82,93 \\
57 & $-2.092,22$ & 119,53 & 82,39 \\
58 & $-2.010,37$ & 119,53 & 81,85 \\
59 & $-1.929,05$ & 119,53 & 81,32 \\
60 & $-1.848,26$ & 119,53 & 80,79 \\
61 & $-1.768,00$ & 119,53 & 80,26 \\
62 & $-1.688,26$ & 119,53 & 79,74 \\
63 & $-1.609,03$ & 119,53 & 79,22 \\
64 & $-1.530,33$ & 119,53 & 78,71 \\
65 & $-1.452,13$ & 119,53 & 78,19 \\
66 & $-1.374,45$ & 119,53 & 77,69 \\
67 & $-1.297,27$ & 119,53 & 77,18 \\
68 & $-1.220,59$ & 119,53 & 76,68 \\
69 & $-1.144,41$ & 119,53 & 76,18 \\
70 & $-1.068,72$ & 119,53 & 75,68 \\
71 & $-993,53$ & 119,53 & 75,19 \\
72 & $-918,83$ & 119,53 & 74,7 \\
73 & $-844,62$ & 119,53 & 74,22 \\
74 & $-770,88$ & 119,53 & 73,73 \\
75 & $-697,63$ & 119,53 & 73,25 \\
76 & $-624,85$ & 119,53 & 72,78 \\
77 & $-552,55$ & 119,53 & 72,3 \\
78 & $-480,72$ & 119,53 & 71,83 \\
79 & $-409,35$ & 119,53 & 71,36 \\
80 & $-338,45$ & 119,53 & 70,9 \\
81 & $-268,01$ & 119,53 & 70,44 \\
82 & $-198,03$ & 119,53 & 69,98 \\
83 & $-128,51$ & 119,53 & 69,53 \\
84 & $-59,44$ & 119,53 & 69,07 \\
85 & 9,19 & 119,53 & 68,62 \\
\hline & & & \\
& & &
\end{tabular}

Nos resultados é possível observar que o Fluxo de caixa se torna positivo no octogésimo quinto mês. Análise equivalente foi realizada para todas as residências, localidades e número de habitantes. O resumo dos resultados para a cidade de Florianópolis, ora citado, pode ser encontrado na tabela 17 e figura 9 a seguir: 
Tabela 17 - Demonstrativo econômico para a cidade de Florianópolis

\begin{tabular}{clrrrr}
\hline \multirow{2}{*}{ Pessoas } & \multicolumn{3}{c}{ Área Telhado [m $\left.^{\mathbf{2}}\right]$} \\
& & $\mathbf{1 0 0}$ & $\mathbf{1 5 0}$ & $\mathbf{2 0 0}$ & $\mathbf{3 0 0}$ \\
\hline \multirow{3}{*}{3} & Economia Água [R\$] & 52,45 & 52,45 & 52,45 & 52,45 \\
& Consumo Luz [R\$] & 0,14 & 0,14 & 0,14 & 0,14 \\
& Benefício Econômico [R\$] & 52,31 & 52,31 & 52,31 & 52,31 \\
& Investimento Inicial [R\$] & $5.238,75$ & $5.514,63$ & $5.808,42$ & $6.399,21$ \\
& Payback [meses] & 164 & 180 & 199 & 248 \\
& Economia Água [R\$] & 95,81 & 95,81 & 95,81 & 95,81 \\
& Consumo Luz [R\$] & 0,19 & 0,19 & 0,19 & 0,19 \\
$\mathbf{4}$ & Benefício Econômico [R\$] & 95,63 & 95,63 & 95,63 & 95,63 \\
& Investimento Inicial [R\$] & $6.602,36$ & $6.667,28$ & $6.961,07$ & $7.551,86$ \\
& Payback [meses] & 93 & 94 & 100 & 112 \\
& Economia Água [R\$] & 119,76 & 119,76 & 119,76 & 119,76 \\
& Consumo Luz [R\$] & 0,23 & 0,23 & 0,23 & 0,23 \\
$\mathbf{5}$ & Benefício Econômico [R\$] & 119,53 & 119,53 & 119,53 & 119,53 \\
& Investimento Inicial [R\$] & $8.268,20$ & $6.878,24$ & $7.172,03$ & $7.762,82$ \\
& Payback [meses] & 93 & 73 & 77 & 85 \\
\hline
\end{tabular}

Fonte: Elaborado pelos autores

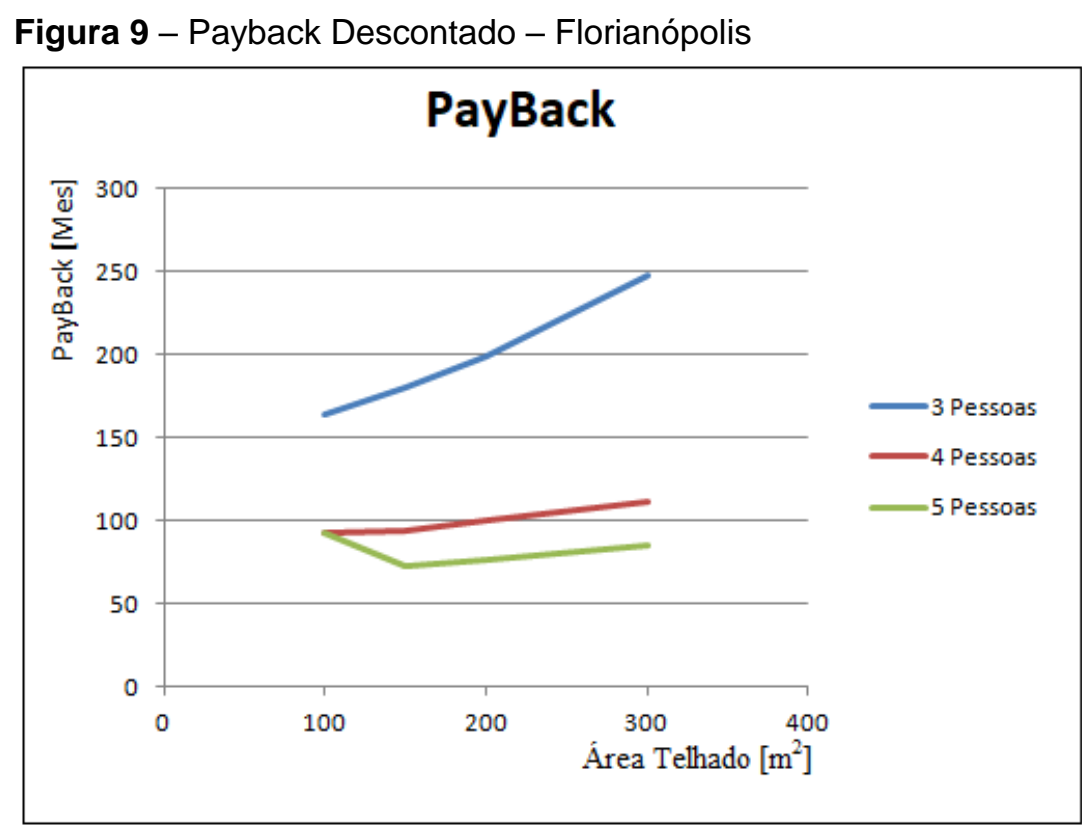

Fonte: Elaborado pelos autores

É possível notar ainda que conforme a variável "número de pessoas" aumenta na análise de sensibilidade, há uma redução gradativa do payback para todos os tamanhos de telhado. Desta forma, as residências com 5 pessoas foram as que oferecem os melhores benefícios econômicos para os quatro tamanhos de telhados (quanto menor o payback, melhor). Apenas na situação de telhados de $100 \mathrm{~m}^{2} \mathrm{com} 4$ ou 5 residentes houve equivalência no tempo de recuperação do capital, alcançando 93 meses. 
Ainda, no comparativo às demais cidades, dispostos nas tabelas 18, 19, 20 e 21, constata-se que Florianópolis foi a que apresentou um menor tempo de retorno do investimento, com 73 meses de payback (ou aproximadamente 6 anos) para um telhado de $150 \mathrm{~m}^{2}$ em residências com cinco pessoas.

Ide, agora, analisar as características das casas das demais cidades interioranas de Santa Catarina, iniciando por Chapecó:

Tabela 18 - Demonstrativo econômico para a cidade de Chapecó

\begin{tabular}{clrrrr}
\hline & & \multicolumn{4}{c}{ Área Telhado [m²] } \\
Pessoas & $\mathbf{1 0 0}$ & $\mathbf{1 5 0}$ & $\mathbf{2 0 0}$ & $\mathbf{3 0 0}$ \\
\hline \multirow{4}{*}{3} & Economia Água [R\$] & 52,45 & 52,45 & 52,45 & 52,45 \\
& Consumo Luz [R\$] & 0,14 & 0,14 & 0,14 & 0,14 \\
& Benefício Econômico [R\$] & 52,31 & 52,31 & 52,31 & 52,31 \\
& Investimento Inicial [R\$] & $6.602,36$ & $6.878,24$ & $7.172,03$ & $7.762,82$ \\
& Payback [meses] & 269 & 303 & 350 & 547 \\
& Economia Água [R\$] & 95,81 & 95,81 & 95,81 & 95,81 \\
& Consumo Luz [R\$] & 0,19 & 0,19 & 0,19 & 0,19 \\
$\mathbf{4}$ & Beneficio Econômico [R\$] & 95,63 & 95,63 & 95,63 & 95,63 \\
& Investimento Inicial [R\$] & $6.602,36$ & $6.878,24$ & $7.172,03$ & $7.762,82$ \\
& Payback [meses] & 93 & 98 & 104 & 177 \\
& Economia Água [R\$] & 119,76 & 119,76 & 119,76 & 119,76 \\
& Consumo Luz [R\$] & 0,23 & 0,23 & 0,23 & 0,23 \\
$\mathbf{5}$ & Benefício Econômico [R\$] & 119,53 & 119,53 & 119,53 & 119,53 \\
& Investimento Inicial [R\$] & $8.268,20$ & $8.544,08$ & $8.837,87$ & $9.428,66$ \\
& Payback [meses] & 93 & 97 & 102 & 112 \\
\hline
\end{tabular}

Fonte: Elaborado pelos autores

Figura 10 - Payback Descontado - Chapecó

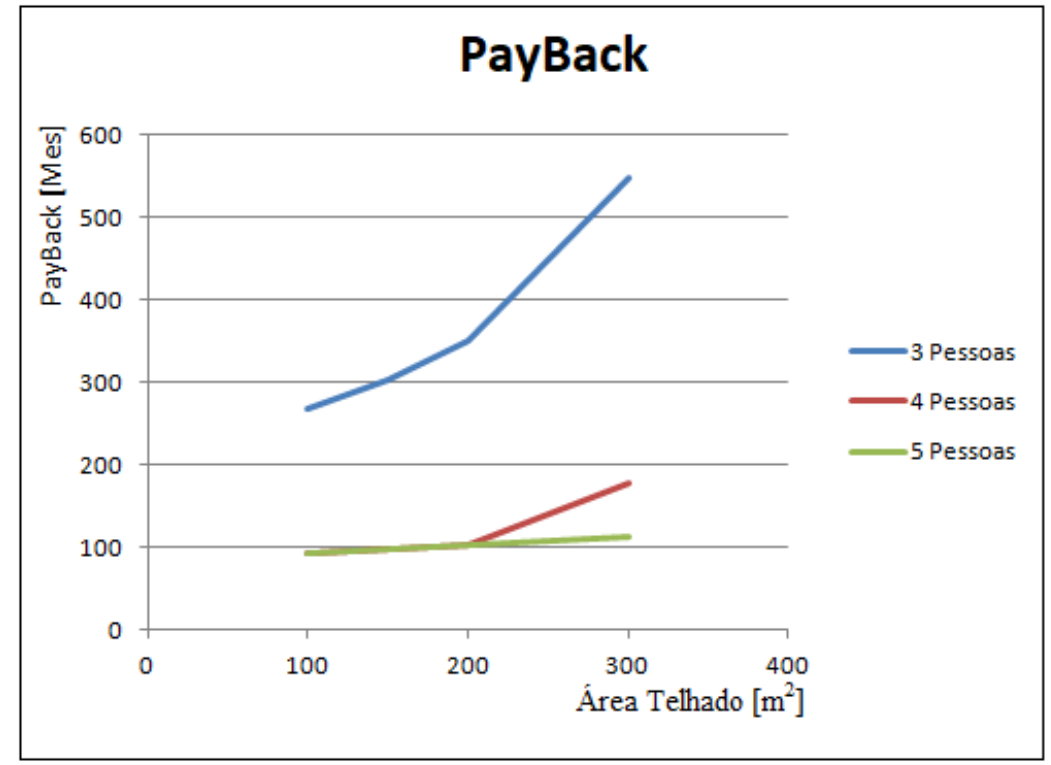

Fonte: Elaborado pelos autores

A principal peculiaridade de Chapecó sobressai aos telhados entre $100 \mathrm{~m}^{2} \mathrm{e}$ $200 m^{2}$ nas residências com 4 e 5 pessoas, apresentando paybacks equivalentes (100 
meses). Após este período, residências com 5 habitantes passam a ser as únicas vantajosas.

Na observação dos resultados da pesquisa de Tam, Tam e Zeng (2010) sobre implantação de tanques para coletas de água de chuva em diversas cidades da Austrália, constataram os municípios de Brisbane, Gold Cost e Sydney obtinham o menor custo em decorrência de sua maior pluviosidade. Portanto, inicialmente era de se esperar que Chapecó tivesse um tempo de retorno de investimento menor que o de Florianópolis, decorrido do custo da água ser o mesmo nas duas cidades e Chapecó apresentar um índice pluviométrico mais elevado. Mas não é isto que se verifica. Uma explicação plausível para este resultado recai na média anual de chuvas de Chapecó apresentar grandes volumes em poucos períodos de tempo e de estiagens maiores, tornando o custo da infraestrutura mais elevado em comparação a Florianópolis. A seguir, demonstrativo de Içara:

Tabela 19 - Demonstrativo econômico para a cidade de Içara

\begin{tabular}{|c|c|c|c|c|c|}
\hline \multirow{2}{*}{ Pessoas } & & \multicolumn{4}{|c|}{ Área Telhado [m²] } \\
\hline & & 100 & 150 & 200 & 300 \\
\hline \multirow{5}{*}{3} & Economia Áqua [R\$] & 52,45 & 52,45 & 52,45 & 52,45 \\
\hline & Consumo Luz $[\mathrm{R} \$]$ & 0,14 & 0,14 & 0,14 & 0,14 \\
\hline & Benefício Econômico [R\$] & 52,31 & 52,31 & 52,31 & 52,31 \\
\hline & Investimento Inicial $[R \$]$ & $6.602,36$ & $6.878,24$ & $6.961,07$ & $6.399,21$ \\
\hline & Payback [meses] & 269 & 303 & 315 & 248 \\
\hline \multirow{5}{*}{4} & Economia Água [R\$] & 95,81 & 95,81 & 95,81 & 95,81 \\
\hline & Consumo Luz [R\$] & 0,19 & 0,19 & 0,19 & 0,19 \\
\hline & Beneficio Econômico [R\$] & 95,63 & 95,63 & 95,63 & 95,63 \\
\hline & Investimento Inicial $[R \$]$ & $8.268,20$ & $6.878,24$ & $7.171,93$ & $7.762,72$ \\
\hline & Payback [meses] & 128 & 98 & 104 & 117 \\
\hline \multirow{5}{*}{5} & Economia Água $[R \$]$ & 119,76 & 119,76 & 119,76 & 119,76 \\
\hline & Consumo Luz [R\$] & 0,23 & 0,23 & 0,23 & 0,23 \\
\hline & Benefício Econômico $[\mathrm{R} \$]$ & 119,53 & 119,53 & 119,53 & 119,53 \\
\hline & Investimento Inicial $[\mathrm{R} \$]$ & $13.075,90$ & $8.544,08$ & $8.837,87$ & $9.428,66$ \\
\hline & Payback [meses] & 194 & 97 & 102 & 115 \\
\hline
\end{tabular}

Fonte: Elaborado pelos autores 


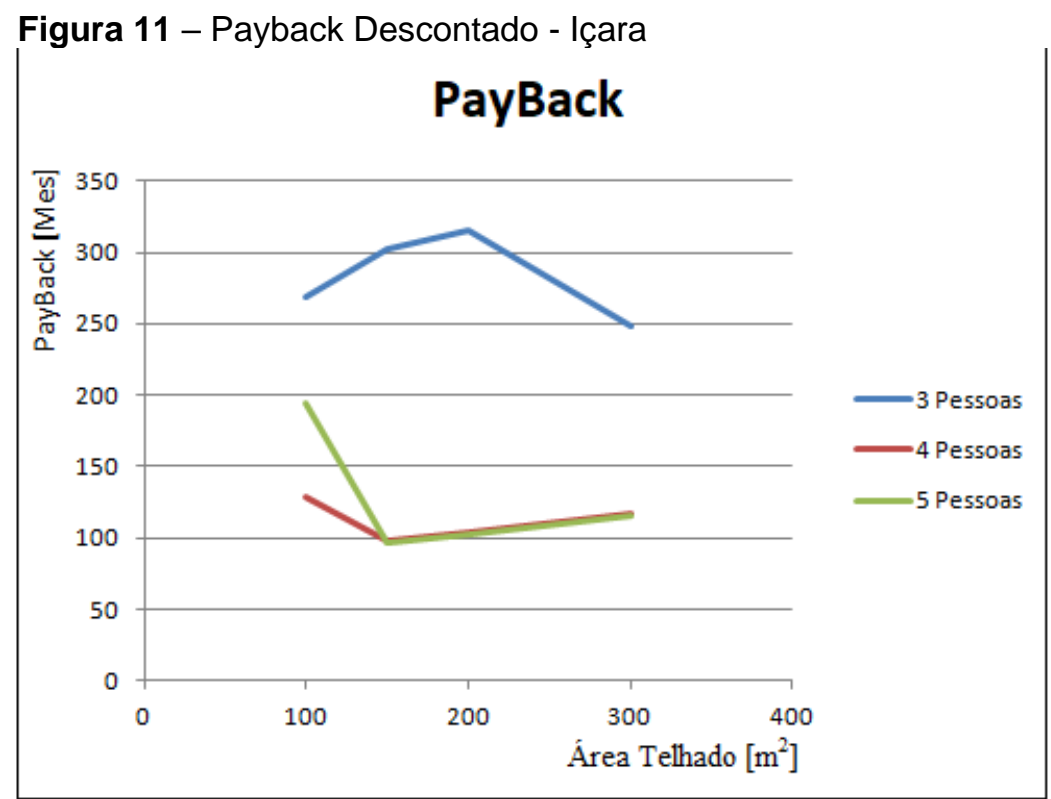

Fonte: Elaborado pelos autores

Içara aportou dois resultados inusitados. Nas residências com 4 pessoas e detentoras de um telhado com $100 \mathrm{~m}^{2}$ houve um payback menor em comparação àquelas de 5 residentes. Todavia, essa situação passa a ser praticamente igualitária para ambas a partir de telhados com $150 \mathrm{~m}^{2}$. O segundo resultado chamativo foi acerca das residências com 3 habitantes: houve um aumento do tempo de retorno do capital entre o menor telhado até o de $200 \mathrm{~m}^{2}$, ingressando em uma redução quando implantado o de maior capacidade $\left(300 \mathrm{~m}^{2}\right)$. Em sequência, demonstrativo e análise gráfica de Joinville:

Tabela 20 - Demonstrativo econômico para a cidade de Joinville

\begin{tabular}{|c|c|c|c|c|c|}
\hline \multirow{2}{*}{\multicolumn{2}{|c|}{ Pessoas }} & \multicolumn{4}{|c|}{ Área Telhado $\left[\mathrm{m}^{2}\right]$} \\
\hline & & 100 & 150 & 200 & 300 \\
\hline \multirow{5}{*}{3} & Economia Água [R\$] & 39,42 & 39,42 & 39,42 & 39,42 \\
\hline & Consumo Luz [R\$] & 0,14 & 0,14 & 0,14 & 0,14 \\
\hline & Benefício Econômico $[\mathrm{R} \$]$ & 35,47 & 35,47 & 35,47 & 35,47 \\
\hline & Investimento Inicial $[\mathrm{R} \$]$ & $5.238,75$ & $5.514,63$ & $5.808,42$ & $6.399,21$ \\
\hline & Payback [meses] & 525 & - & - & - \\
\hline \multirow{5}{*}{4} & Economia Água [R\$] & 72,00 & 72,00 & 72,00 & 72,00 \\
\hline & Consumo Luz $[\mathrm{R} \$]$ & 0,19 & 0,19 & 0,19 & 0,19 \\
\hline & Benefício Econômico [R\$] & 64,80 & 64,80 & 64,80 & 64,80 \\
\hline & Investimento Inicial $[\mathrm{R} \$]$ & $6.391,40$ & $6.667,28$ & $6.961,07$ & $7.551,86$ \\
\hline & Payback [meses] & 160 & 172 & 187 & 221 \\
\hline \multirow{5}{*}{5} & Economia Água $[R \$]$ & 90,00 & 90,00 & 90,00 & 90,00 \\
\hline & Consumo Luz $[\mathrm{R} \$]$ & 0,23 & 0,23 & 0,23 & 0,23 \\
\hline & Benefício Econômico [R\$] & 81,00 & 81,00 & 81,00 & 81,00 \\
\hline & Investimento Inicial $[\mathrm{R} \$]$ & $6.602,36$ & $6.878,24$ & $7.172,03$ & $7.762,82$ \\
\hline & Payback [meses] & 117 & 125 & 133 & 152 \\
\hline
\end{tabular}

Fonte: Elaborado pelos autores

Figura 12 - Payback Descontado - Joinville 


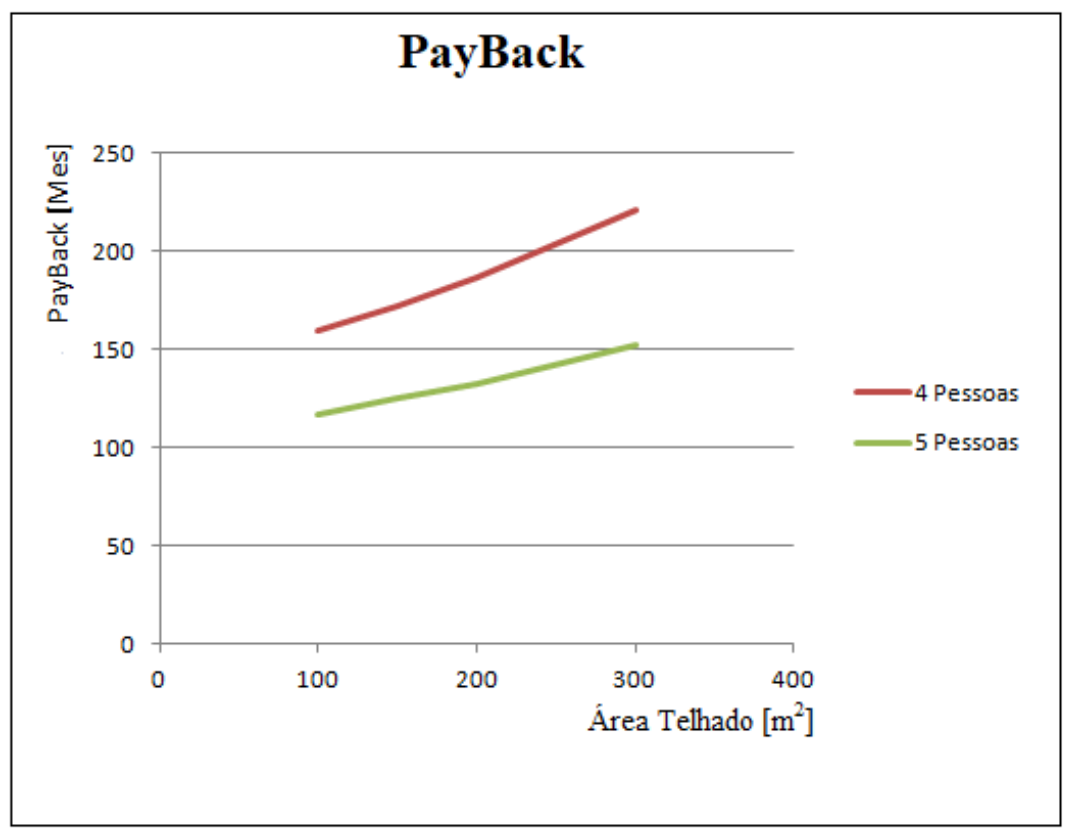

Fonte: Elaborado pelos autores

Em Joinville, assim como nas cidades anteriores, o campeão foi o projeto de residência com 5 habitantes. O diferencial da cidade foi a ausência de retorno do capital para residências com 3 habitantes a partir do uso de telhados com $150 \mathrm{~m}^{2} \mathrm{e}$ aumento progressivo do pabyack no comparativo às residências com 4 e 5 pessoas. Finalizando as análises, os resultados incorridos para Lages:

Tabela 21 - Demonstrativo econômico para a cidade de Lages

\begin{tabular}{|c|c|c|c|c|c|}
\hline \multirow{2}{*}{\multicolumn{2}{|c|}{ Pessoas }} & \multicolumn{4}{|c|}{ Área Telhado $\left[\mathrm{m}^{2}\right]$} \\
\hline & & 100 & 150 & 200 & 300 \\
\hline \multirow{5}{*}{3} & Economia Água $[R \$]$ & 32,63 & 32,63 & 32,63 & 32,63 \\
\hline & Consumo Luz [R\$] & 0,14 & 0,14 & 0,14 & 0,14 \\
\hline & Benefício Econômico [R $\$$. & 32,49 & 32,49 & 32,49 & 32,49 \\
\hline & Investimento Inicial [R $\$]$ & $6.391,406$ & 667,286 & (1) & \\
\hline & Payback [meses] & - & - & - & \\
\hline & {$[\mathrm{R} \$]$} & 59,61 & 59,61 & 59,61 & 59,61 \\
\hline & Cons & 0,19 & 0,19 & 0,19 & 0,19 \\
\hline & Beneficio Econômico [R $\$$ & 59,42 & 59,42 & 59,42 & 59,42 \\
\hline & Investimento Inicial $[R \$]$ & $6.602,36$ & $.878,247$ & $.172,03$ & $.762,82$ \\
\hline & Payb & 200 & 218 & 240 & 197 \\
\hline \multirow{5}{*}{5} & Água $[R \$]$ & 74,51 & 74,51 & 74,51 & 74,51 \\
\hline & Consumo Luz [R\$] & 0,23 & 0,23 & 0,23 & 0,23 \\
\hline & Benefício Econômico [R $\$$ & ] $\quad 74,28$ & 74,28 & 74,28 & 74,28 \\
\hline & Investimento Inicial [R\$] & $12.188,346$ & $.878,247$ & $.172,03$ & $.762,82$ \\
\hline & Payback [meses] & & 143 & 154 & 177 \\
\hline
\end{tabular}

Fonte: Elaborado pelos autores 
Figura 13 - Payback Descontado - Lages

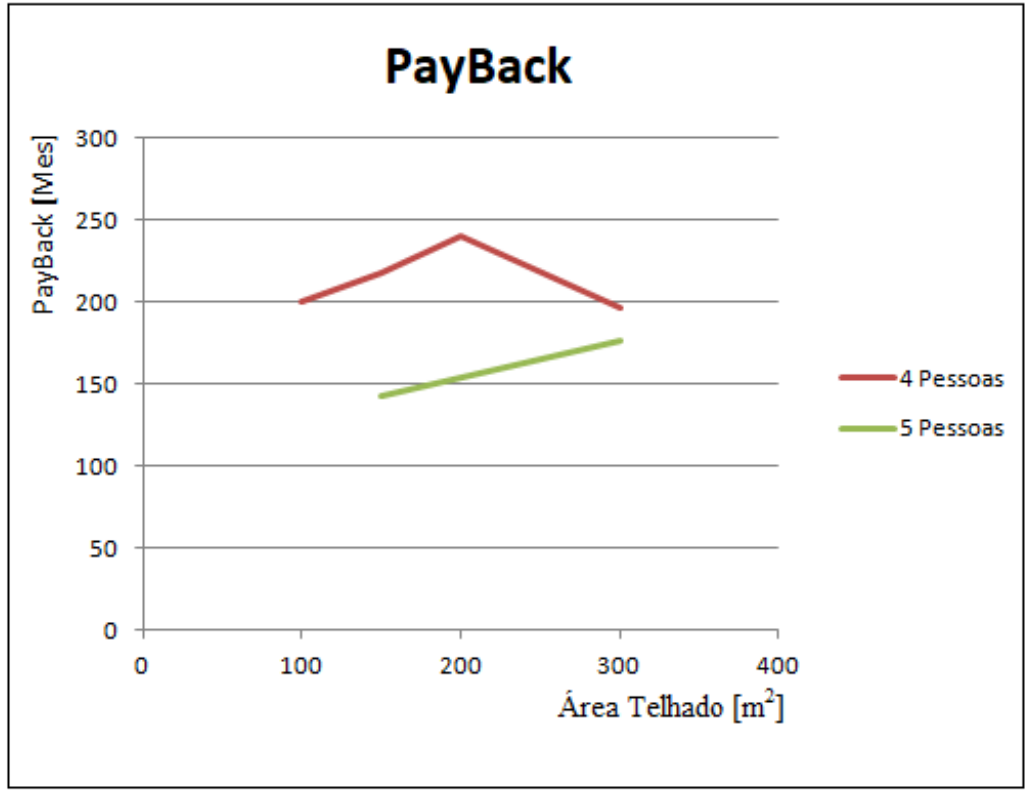

Fonte: Elaborado pelos autores

Lages, finalizando as análises, não incorreu em retorno do capital investido para todos os tamanhos de telhados nas residências com 3 habitantes. Apresentou o menor payback para casas com 5 pessoas a partir de telhados com $150 \mathrm{~m}^{2}$, decorrido que aquelas comportando $100 \mathrm{~m}^{2}$ também não apresentaram retorno do investimento. No quesito das instalações para 4 residentes, iniciou-se com 200 meses de payback, aumentando gradativamente até telhados com $200 \mathrm{~m}^{2}$ e regredindo para 197 meses com o telhado de maior capacidade.

\section{CONSIDERAÇÕES FINAIS}

Através do presente estudo conclui-se que o aproveitamento de água da chuva coletada através de telhados e submetida a um tratamento para desinfecção de bactérias é plenamente viável em expressiva parte das situações analisadas. Este achado de pesquisa foi possível devido ao cumprimento do objetivo específico de desenvolvimento de dois softwares em PHP e HTML (SILVA, 2017a, 2017b). As configurações instauradas nestes possibilitaram efetivar uma análise de sensibilidade, calculando os dimensionamentos dos reservatórios de água de chuva e posteriormente os cálculos do payback descontado para cada situação de modificação da quantidade de residentes e de tamanho dos telhados, aplicados a regimes 
pluviométricos diferenciados em cidades de distintas regiões do estado de Santa Catarina.

Para famílias com três pessoas, o consumo é de 13.392 litros de água por mês, sendo 8.745 de água potável e 4.658 de água não potável que pode ser substituído por água da chuva. Verifica-se que o volume de água consumida está muito próximo ao volume de 10.000 litros, equivalente a taxa mínima oferecida pelas concessionárias. Dessa forma, para Florianópolis, o melhor tempo de retorno do investimento para uma família de três pessoas foi de 164 meses, aproximadamente 14 anos.

$\mathrm{Na}$ situação de residências com 4 indivíduos, o período mínimo para recuperação do capital é de 93 meses para Florianópolis e Chapecó, podendo chegar até a 297 meses em Lages. Nesse ponto, duas variáveis devem ser analisadas. Na cidade que apresenta o menor índice pluviométrico, Içara, há um período de recuperação de capital de 128 meses. Menores índices pluviométricos indicam que devem ser utilizados equipamentos com maior capacidade de armazenamento, representando maior custo de investimento. No entanto, cidades como Joinville e Lages que apresentam um maior índice pluviométrico, resultam em um maior período de recuperação de capital em consequência às suas menores tarifas de água praticada pelas concessionárias que atuam nestas cidades.

$\mathrm{Na}$ consideração de residências com famílias comportando cinco pessoas, o menor período para a recuperação do capital foi de 73 meses para a cidade de Florianópolis, ou seja, 6 anos e um mês. Portanto, sob o aspecto econômico, foi possível proceder à seguinte síntese: consumo de água próximo à taxa mínima, não vale a pena substituir. Residências com uma área de captação maior e poucas pessoas ocupando a mesma, a viabilidade se torna menor, uma vez que, a quantidade de calhas encarece o projeto, tornando o investimento maior. Aumentando-se a densidade populacional por habitação, o atrativo para a substituição aumenta. Quanto maior for a precipitação média, os reservatórios se tornam menores e mais baratos, possibilitando o sistema ser mais atrativo financeiramente.

\section{REFERÊNCIAS}

ABNT. ASSOCIAÇÃO BRASILEIRA DE NORMAS TÉCNICAS. NBR 15527: Água de chuva - Aproveitamento de coberturas em áreas urbanas para fins não potáveis. Rio de Janeiro: 2007. 
ANA. AGÊNCIA NACIONAL DE ÁGUAS. Atlas Brasil: Abastecimento Urbano de Água: Panorama Nacional 2010. Disponível em: <http://atlas.ana.gov.br/Atlas/forms/Home.aspx>. Acesso em: 8 jul. 2017.

ASSAF NETO, Alexandre. Finanças corporativas e valor. 6. ed. São Paulo: Atlas, 2012. CANLOFFSKI, Rodrigo. Análise de Investimentos e Viabilidade Financeira das Empresas. São Paulo: Atlas, 2014.

CASAN. Tabela tarifária de 2017. 2017. Disponível em: $<$ http://www.casan.com.br/noticia/index/url/tabela-tarifaria-de-2017\#1700>. Acesso em: 04 set. 2017.

CASAROTTO-FILHO, Nelson. KOPITTKE, Bruno Hartmut. Análise de investimentos: matemática financeira, engenharia econômica tomada de decisão, estratégica empresarial, 11. ed. São Pulo: Atlas, 2010.

CELESC. Disponível em: <http://www.celesc.com.br/portal/>. Acesso em: 05/06/2017.

COMPANHIA ÁGUAS DE JOINVILLE - Águas de Joinville. Tabela tarifária - tarifas de água e esgoto. Disponível em: <http://www.aguasdejoinville.com.br/site/?page $i d=2>$. Acesso em: 04 set. 2017.

EROKSUZ, Erhan; RAHMAN, Ataur. Rainwater tanks in multi-unit buildings: A case study for three Australian cities. Resources, Conservation And Recycling, v. 54, n. 12, p.14491452, out. 2010. Elsevier BV. http://dx.doi.org/10.1016/i.resconrec.2010.06.010.

GITMAN, Lawrence J. Princípios de Administração Financeira. 7. ed. São Paulo: Harbra, 2002.

GHISI, Enedir; SCHONDERMARK, Pedro Neves. Investment Feasibility Analysis of Rainwater Use in Residences. Water Resources Management, v. 27, n. 7, p.2555-2576, 17 fev. 2013. Springer Nature. http://dx.doi.org/10.1007/s11269-013-0303-6.

GROPPELLI, A.A; NIKBAKHT, Ehsan. Administração Financeira. 2. ed. São Paulo: Saraiva, 2006.

INMET. Instituto Nacional De Meteorologia. BDMEP - Banco de dados meteorológicos para ensino e pesquisa, Disponível em:<http://www.inmet.gov.br/portal/index.php?r=bdmep/bdmep>. Acesso em: 30 jul. 2017.

IMTEAZ, Monzur Alam et al. Optimisation of rainwater tank design from large roofs: A case study in Melbourne, Australia. Resources, Conservation And Recycling, [s.I.], v. 55, n. 11, p.1022-1029, set. 2011. Elsevier BV. http://dx.doi.org/10.1016/j.resconrec.2011.05.013.

KHASTAGIR, Anirban; JAYASURIYA, Niranjali. Investment Evaluation of Rainwater Tanks. Water Resources Management, v. 25, n. 14, p.3769-3784, 20 jul. 2011. Springer Nature. http://dx.doi.org/10.1007/s11269-011-9883-1.

MARINOSKI, Ana Kelly. Aproveitamento de Água Pluvial Para Fins Não Potáveis Em Instituição de Ensino: Estudo De Caso Em Florianópolis - SC. 2007. 107 f. TCC (Graduação) - Curso de Engenharia Civil, Engenharia Civil, Universidade Federal de Santa Catarina, Florianópolis, 2007. 
OLIVEIRA, José Augusto et al. Identificação dos benefícios e dificuldades da produção mais limpa em empresas industriais do estado de São Paulo. Revista Produção Online, v. 15, n. 2, p.458-481, 15 jun. 2015. Associacao Brasileira de Engenharia de Producao - ABEPRO. http://dx.doi.org/10.14488/1676-1901.v15i2.1751.

PATZLAFF, Jeferson Ost; KERN, Andrea Parisi; GONZÁLEZ, Marco Aurélio Stumpf. Projeto de edificações com apelo sustentável: elementos para a construção de um sistema de apoio à decisão. Revista Produção Online, v. 10, n. 3, p.479-503, 25 ago. 2010. Associacao Brasileira de Engenharia de Producao - ABEPRO. http://dx.doi.org/10.14488/1676$\underline{1901 . v 10 i 3.157}$

ROSS, Sthephen; WESTERFIELD, Randolph W; JAFFE, Jeffrey F. Administração Financeira. 2. ed. São Paulo: Atlas, 2010.

CPRM. SERVIÇO GEOLÓGICO DO BRASIL. Coisas que você deve saber sobre a água. 2016. Disponível em: <http://www.cprm.gov.br/publique/Redes-Institucionais/Rede-deBibliotecas---Rede-Ametista/Canal-Escola/Coisas-que-Voce-Deve-Saber-sobre-a-Agua1084.html>. Acesso em: 30 jul. 2017.

SILVA, Carlos Eduardo da. Dimensionamento reservatórios água chuva. 2017a. Disponível em: <http://ceduardosilva.com.br/Chuva2017/chuva.html>. Acesso em: 9 ago. $2017 a$.

SILVA, Carlos Eduardo da. Cálculo payback investimento. 2017b. Disponível em: <http://ceduardosilva.com.br/Chuva2017/PayBack.html>. Acesso em: 8 out. 2017b.

SILVA FILHO, Antonio Romão Alves da. Sistema de gestão ambiental como estratégia empresarial no ramo hoteleiro. Revista Produção Online, v. 8, n. 3, 25 set. 2008.

Associacao Brasileira de Engenharia de Producao - ABEPRO.

http://dx.doi.org/10.14488/1676-1901.v8i3.110.

SCHNEIDER. Produtos. Disponível em: <http://www.schneider.ind.br/produtos/> . Acesso em: 15/08/2017.

SNIS. Ministério das Cidades. Sistema Nacional de informações sobre saneamento: diagnóstico dos serviços de água e esgotos - 2015. Disponível em $<$ http://www.cidades.gov.br/serieHistorica>, Acesso em 20/08/2017.

SOUZA, Acilon Batista. Projetos de Investimentos de Capital: elaboração, análise e tomada de decisão. São Paulo: Editora Atlas, 2003.

TAM, Vivian W.y.; TAM, Leona; ZENG, S. Cost effectiveness and tradeoff on the use of rainwater tank: An empirical study in Australian residential decision-making. Resources, Conservation And Recycling, v. 54, n. 3, p.178-186, jan. 2010. Elsevier BV.

http://dx.doi.org/10.1016/j.resconrec.2009.07.014.

TORRE, Paloma Yara Guimarães; ALVES, Jean Carlos Machado; CORRêA, Savio Figueira. Análise de eficiência energética para indústria têxtil: um estudo de caso em uma empresa de Minas Gerais. Revista Produção Online, v. 18, n. 1, p.238-264, 15 mar. 2018. Associacao Brasileira de Engenharia de Producao - ABEPRO. http://dx.doi.org/10.14488/16761901.v18i1.2762.

VILLARREAL, Edgar L.; DIXON, Andrew. Analysis of a rainwater collection system for domestic water supply in Ringdansen, Norrköping, Sweden. Building And Environment, v. 
40, n. 9, p.1174-1184, set. 2005. Elsevier BV.

http://dx.doi.org/10.1016/j.buildenv.2004.10.018.

ZANELLA, Luciano. Manual para captação emergencial e uso doméstico de água de chuva [livro eletrônico].São Paulo: IPT - Instituto de Pesquisas Tecnológicas do Estado de São Paulo, 2015.

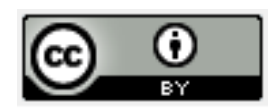

Artigo recebido em: 19/12/2017 e aceito para publicação em: 31/03/2018

DOI: http://dx.doi.org/10.14488/1676-1901.v18i3.3115 